\title{
A narrative review of intraocular lens opacifications: update 2020
}

\author{
Andrzej Grzybowski ${ }^{1,2}$, Agne Markeviciute ${ }^{3}$, Reda Zemaitiene ${ }^{3}$ \\ ${ }^{1}$ Department of Ophthalmology, University of Warmia and Mazury, Olsztyn, Poland; ${ }^{2}$ Institute for Research in Ophthalmology, Poznan, Poland; \\ ${ }^{3}$ Department of Ophthalmology, Medical Academy, Lithuanian University of Health Sciences, Kaunas, Lithuania \\ Contributions: (I) Conception and design: A Grzybowski; (II) Administrative support: A Grzybowski, R Zemaitiene; (III) Provision of study materials \\ or patients: None; (IV) Collection and assembly of data: A Grzybowski, A Markeviciute; (V) Data analysis and interpretation: A Grzybowski, A \\ Markeviciute; (VI) Manuscript writing: All authors; (VII) Final approval of manuscript: All authors. \\ Correspondence to: Andrzej Grzybowski, MD, PhD, MBA. Institute for Research in Ophthalmology, Gorczyczewskiego 2/3, 61-553 Poznan, Poland. \\ Email: ae.grzybowski@gmail.com.
}

\begin{abstract}
The opacifications of intraocular lenses (IOLs) can significantly impact patients visual quality. Despite the identification of specific risk factors, manufacturing changes, opacifications are not eliminated. Likewise, more attention in recent studies was paid to possible new risk factors, however one of the most important purposes of the studies remains opacifications effect on visual performance, which could be disturbed in different aspects. The aim of this review is to discuss the main risk factors of IOLs opacification in particular IOL types, and its impact on vision quality. Different risk factors were discussed in the study, including the material of IOLs, the impact of the breakdown of blood-aqueous barrier (BAB), and certain surgeries that can be associated with opacification formation. Glistenings occur more often in a hydrophobic material, however, the changes in water content of the IOLs can significantly reduce the formation of glistenings. The studies showed a significant effect of intraocular injection of exogenous air or gas during Descemet-stripping endothelial keratoplasty, Descemet-stripping automated endothelial keratoplasty, Descemet membrane endothelial keratoplasty, and pars plana vitrectomy on calcification formation. It raises a concern, as the incidence of these surgeries is increasing. Visual acuity decreases significantly after the calcification in IOLs occurs, and it usually causes IOLs exchange. However, disability glare seems to be more affected in patients with IOLs, which were affected by glistenings than visual acuity. Disability glare is associated with increased levels of straylight, which was widely evaluated in recent studies and it was reported to be a susceptible measurement to detect the presence of IOLs pathology. For future researches, it should be noticed that disability glare and straylight are more appropriate in evaluating IOLs opacification effect on visual quality than visual acuity. While reviewing the main risk factors of IOLs opacifications particular attention must be paid on calcification occurrence in hydrophilic acrylic IOLs after surgeries with intraocular injection of exogenous air or gas.
\end{abstract}

Keywords: Intraocular lens; opacification; glistening; subsurface nanoglistenings; calcification

Submitted May 23, 2020. Accepted for publication Jul 10, 2020.

doi: $10.21037 /$ atm-20-4207

View this article at: http://dx.doi.org/10.21037/atm-20-4207

\section{Introduction}

Twenty million cataract surgeries are being performed annually worldwide defining it as the most common surgery (1). Nearly five million cataract surgeries were performed in Europe in 2017 (2). It was estimated that in the Unites States 9.5 million people would have pseudophakia by 2020 (3). The main purpose of intraocular lenses (IOLs) that are implanted during cataract surgery is to restore vision (1). Their performance depends on different factors, including surgical technique, possible complications, lens biomaterial and design, and host reaction (4). Posterior capsular opacification (PCO) occurs in $10 \%$ of patients two years after cataract surgery and is 
the most common of long-term complications (5). After 5-7 years the incidence may rise to 30-35\% (6). Vock et al. reported that $42 \%$ of the eyes needed Nd:YAG laser capsulotomy due to the PCO 10 years after surgery (7).

It develops from remaining lens epithelial cells, which proliferate and migrate over the posterior lens capsule (8). Other postoperative late complications include cystoid macular edema, retinal detachment, endophthalmitis, lens dislocation, and IOL opacification (5). The IOL's biomaterial is one of the most critical factors leading to possible post-surgery complications, such as posterior and anterior capsule or IOL opacification formation (3). The main IOLs materials are hydrophobic, or hydrophilic acrylate, polymethylmethacrylate (PMMA), and silicone (9). Different types of material are associated with different types of IOLs opacifications, which include photochemical material alterations, precipitations and depositions, glistenings, and discoloration (1). Snowflake degeneration occurred as intraoptic spherical lesions of PMMA material lenses in the central and midperipheral portion of the optic (10). Silicone IOLs were the first foldable lenses and were known to undergo brownish discoloration and central haze within the first 6 weeks postoperatively (11). The hydrophobic acrylic lenses have been known to show glistenings, while calcifications develop more often in hydrophilic acrylic lenses (11).

Acrylic foldable IOLs have become the most popular type of IOLs that are implanted during cataract surgery (9). It was reported that Alcon hydrophobic acrylic IOLs are one of most commonly implanted, and since 1955, over 40 million such IOLs have been implanted $(12,13)$. However, hydrophilic IOLs have different water content, which makes them more flexible and implantable through smaller incisions than hydrophobic lenses $(11,14,15)$. Hydrophilic IOLs have better tissue compatibility, though it encourages lens epithelial cell proliferation and migration, leading to posterior capsule opacifications (4). The incidence of postoperative complications, including posterior capsule opacifications, was noticed to be lower with acrylic IOLs than with other materials, and with the lowest incidence in hydrophobic lenses $(16,17)$. Leydolt et al. performed a randomized controlled study and found that new hydrophobic acrylic Vininex XY1 IOLs had significantly lower PCO rates than hydrophobic AcrySof SN60WF IOLs, which were considered to have one of the lowest PCO rates (18). It was reported that anterior capsule opacification and phimosis were significantly less observed in the Tecnis IOLs with a continuous edge than in AcrySof
IOLs with an interrupted sharp optic edge $(8,19)$. However, neither of the acrylic lenses is free of material opacification and degradations, which are infrequent but can reduce visual performance (1).

Data about IOL opacification impact on visual acuity is controversial. While the majority of the peer-reviewed studies did not show a significant impact of glistenings and subsurface nanoglistenings on visual acuity, there are recent data about its significant effect on straylight $(1,12,20)$. Increased straylight can result in disability glare, hazy vision, and loss of contrast (21). The main sources of light scattering in the eye are the crystalline lens, cornea, fundus reflectance, and light transmittance by sclera and iris (22). Due to the aging processes, including cataract formation, the straylight increases to an average of 1.20 $\log (\mathrm{s})$ at 65 years of age, while in youth, the straylight value is on average $0.90 \log (\mathrm{s})(22)$. Although straylight decreases significantly after cataract surgery, some of the studies results show high straylight values in pseudophakic eyes (21). This can be determined by the changes in the IOL material such as calcification, glistenings, subsurface nanoglistenings, which can increase the light scattering, therefore having an impact on visual quality $(21,23)$.

The aim of this review is to discuss the recent literature on IOL opacifications and their impact on vision quality.

We present the following article in accordance with the narrative review reporting checklist (available at http:// dx.doi.org/10.21037/atm-20-4207).

\section{Methods}

PubMed was used for the medical literature search, which was conducted up to Apr 7, 2020. The following keywords were used in various combinations: cataract surgery, phacoemulsification, intraocular lens, opacification, glistening, subsurface nanoglistenings, calcification, snowflake degeneration. Only articles having English abstracts were reviewed. The reference lists of identified publications were also considered as a potential source of relevant articled. Studies were critically reviewed to create an overview and guidance for further search, and no attempts to discover unpublished data were made. Emphasis was placed on articles published since 2010, however, we focused mainly on the risk factors for IOL opacification in particular IOL types. In addition to the literature search, selected chapters from relevant textbooks were included if necessary. Due to the large number of studies, in the tables we have presented only original studies and case series, but 


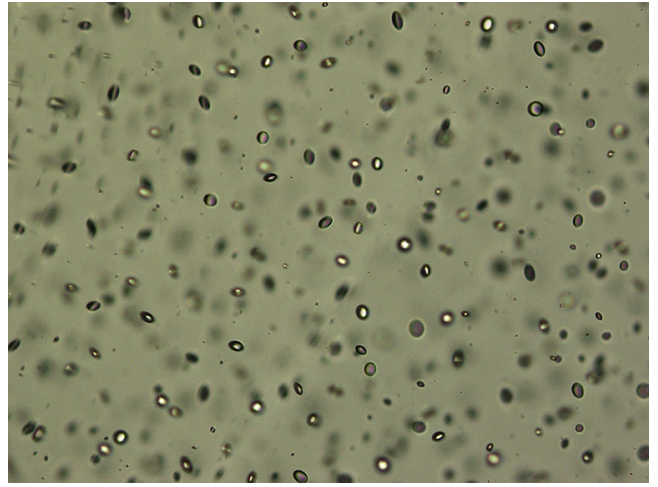

Figure 1 Light photomicrograph of a hydrophobic acrylic IOL explanted because of error in power calculation. The presence of microvacuoles (glistenings) can be seen, within the optic substance of the lens (x200). Courtesy: Liliana Werner, MD, PhD, University of Utah.

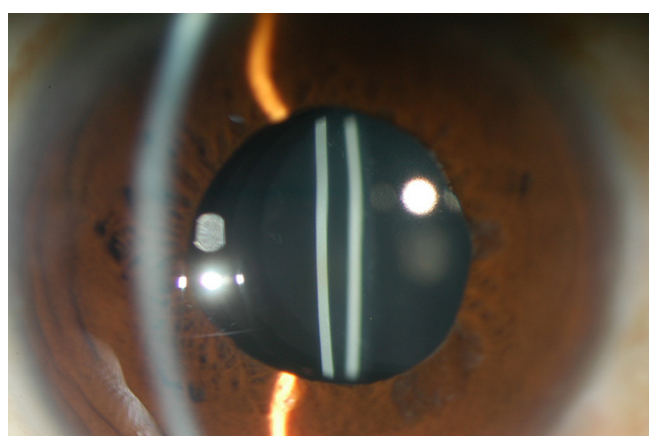

Figure 2 Subsurface nanoglistening (whitening) of the implanted IOL. Courtesy: Hiroyuki Matsushima, MD, PhD, Dokkyo Medical University.

not single case reports.

\section{Glistenings}

Glistenings are small fluid-filled vacuoles in the IOL material (Figure 1), which size usually varies between 1 and $20 \mu \mathrm{m}$ (24). Microvacuoles refractive indices differ from IOL material, so when the light redirects and a portion of the light is scattered backward to the observer, it is seen as refractive particles that glisten on a slit lamp examination $(1,20)$.

One of the main theories of glistenings formation was described by Kato et al. in 2001 (25). They concluded that small changes in temperature could cause the decompensation of the IOL swollen polymer network, initiating the formation of microvacuoles, which consists of water and loosely packed network chains (25). Saylor and colleagues reported that the water-filled cavities could develop due to osmotic pressure differences between the aqueous solution within the cavity and the external liquid in which the lens is immersed (26). As a result of these mechanisms, water permeates micro-channels within the IOL material and forms small inclusions (1). They can be distributed throughout the entire lens optic, but most often are seen in the anterior and posterior IOL surfaces (27). In addition to these proposed mechanisms, IOLs manufacturing methods and packaging might also have an impact on glistening formation as well as its material itself (13). It is known that osmotic and temperature changes are important components in the mechanism of glistening formation $(1,25,26)$. However, the breakdown of the bloodaqueous barrier $(\mathrm{BAB})$ and intraocular inflammatory factors might also have a significant impact on the development of glistening (1). BAB is known to be damaged in diabetes mellitus, uveitis, postoperative inflammation, glaucoma, so that these pathologies may induce the formation of glistening $(28,29)$.

Subsurface nanoglistening can be referred to as whitening (Figure 2) of the hydrophobic acrylic IOL affecting the surface or subsurface of the IOL (differently from glistening, which occur within the substance of IOL) $(30,31)$. The formation of these vacuoles is caused by an infiltration of water molecules that can form aggregates within the subsurface of the lens optic $(1,12,30,31)$. Nanovacuoles diameter is less than one $\mu \mathrm{m}$ (between 140 and $185 \mathrm{~nm})(1,32)$. Ong et al. reported that the main source of hydrophobic acrylic IOL surface light scattering was subsurface nanoglistening (32).

Glistening can be found in all IOL materials, including PMMA, silicone, and hydrophilic acrylic IOLs, but they are observed predominantly in hydrophobic acrylic lenses, which are one of the most commonly used $(24,27,28,33)$. It was reported that glistening in hydrophobic acrylic lenses have higher density $(16,33)$. However, Łabuz et al. reported that different types of hydrophobic acrylic IOLs also differ in their resistance to glistening formation (20). The majority of studies showed a tendency of glistening formation in hydrophobic acrylic lenses that were manufactured by Alcon company (1). The incidence of glistening in AcrySof IOLs increases with time, and it varies from $66 \%$ to $100 \%$ between published studies results (1). Colin et al. reported the formation of glistening in $86.5 \%$ of implanted AcrySof SN60WF IOLs, despite manufacturing changes (34). 
However, Miyata et al. reported that the improved manufacturing process of AcrySof IOLs suppressed the development of surface light scattering up to 3 years postoperatively (35). It was proposed that other types of hydrophobic acrylic IOLs like enVista (manufactured by Bausch and Lomb) are glistening free clinically (36). Glistening were not noticed to occur in iMics1 NY60 when compared with the AcrySof SN60WF 3 years after surgery (37). It was found that recently developed hydrophobic acrylic materials that have a higher water content than the standard (less than $0.5 \%$ ), which include the enVista MX60, the Eternity W-60, PodEye IOLs are glistenings-free in vitro and in vivo (23). Werner et al. compared new Clareon CNA0T0 IOLs, which have a water content of $1.5 \%$ with 5 other hydrophobic IOLs (23). The authors found that the Clareon showed the lowest levels of surface haze, surface roughness, subsurface nanoglistening, and glistening (23).

Although hydrophobicity is an important factor in glistening formation, however visual quality may be influenced by glistening properties and their impact on different optical parameters.

Philippaki et al. compared glistening formation, their size, and its effect on straylight between the Alcon AcrySof SN60WF and Santen Eternity Natural Uni NW-60 IOLs (13). However, the authors suggested to evaluate their results carefully, as they had not had the information if the used IOLs were manufactured before or after the changes of manufacturing process that were announced by Alcon in 2011 (13). Nevertheless, they found a statistically significantly higher number of glistening produced in Alcon AcrySof SN60WF while Eternity Natural Uni NW-60 IOLs developed larger glistening (13). Forward light scattering for the AcrySof lenses, which produced smaller, but greater density glistening, was higher than for the Eternity Natural Uni lenses (13). These results were similar to Labuz et al. study results, which showed that there is a proportional relationship between the number and the surface portion of glistening and their effect on straylight (38). More studies found similar results, concluding that glistening of the smaller size and higher density increased the light scattering more $(39,40)$.

Matsushima et al. reported that glistening and subsurface nanoglistenings caused decreased vision in 5 patients, leading to IOL explantation, which followed the improvement of visual acuity (12). However, the majority of the studies did not find a significant reduction of visual acuity caused by glistening or subsurface nanoglistening
$(1,16,34,35,41-43) . \mathrm{Xi}$ with colleagues, reported that more severe glistening caused the reduction of contrast sensitivity at a high spatial frequency and visual field. They suggested that the mean deviation (MD) can be considered to be used as an indicator for the visual performance of glistening in IOLs (44). The significant decrease of contrast sensitivity at high spatial frequencies with a higher grade of glistening severity was reported by Schweitzer et al. (41). The study results also showed a significant association between the incidence of glistening (61.2\% including grades 1 and 2 ) and the number of topical glaucoma drugs. The disruption of $\mathrm{BAB}$ can be caused by inflammation, chronic use of glaucoma eye drops (41). These were suggested as possible factors that may impact the development of a higher number of glistening associated with the daily use of glaucoma drops (41). Godlewska et al. performed a study with 252 patients undergoing phacoemulsification with AcrySof IQ IOLs implantation, to evaluate the effect of selected perioperative factors and concomitant diseases to glistening formation. They reported a significantly higher severity of glistening in patients with diabetes, which may influence the breakdown of physiological intraocular barriers (45). A higher refractive power of the intraocular lens and the use of bigger diameter cartridge during phacoemulsification were significantly related to the higher severity of glistening (45). The higher refractive power of the IOL can be associated with the increase in glistening severity due to the thicker IOL matrix and the higher amount of material $(24,42)$. However, other studies did not find a correlation between the IOLs power and the number of glistening in hydrophobic AcrySof IOLs $(44,46)$.

Nevertheless, more studies showed that glistening could degrade vision by inducing glare symptoms more than lowering visual acuity or contrast sensitivity $(20,38)$. The optical performance of IOL is usually evaluated by using the modulation transfer function (MTF), which describes the ability of an IOL to project light from an object onto the retina for different spatial frequencies $(47,48)$. Light scattering from an IOL is quantified as straylight and is used to measure a patient's glare symptoms $(46,47)$. This parameter is becoming an essential aspect of vision quality evaluation (47-49). In laboratory studies, straylight can be quantified using a clinical device (50). It was reported that straylight is a susceptible measurement to detect the presence of IOL pathology, including opacifications. However, MTF as the optical quality of IOL deteriorates if the opacification is severe (51). The correlation between IOL structural changes, including opacification, and straylight was found in 
Łabuz et al. study, where IOLs were randomly extracted from donor's eyes (21). The results were compared with another study, conducted by the same author, where glistening was induced in vitro $(19,21)$. The authors indicated that scattering effects of in vitro induced glistening could be compared to glistening that form in vivo (20).

The straylight increases with age as the crystalline lens ages, and decreases after cataract surgery (20). However, Łabuz et al. reported that $20 \%$ of studied IOLs had an increased level of straylight (an average straylight parameter of $18.1 \mathrm{deg}^{2} / \mathrm{sr}$ ), which could be compared with a 70 to 80 -year-old crystalline lens induced straylight (20). The results of this study were affected by glistening formation in hydrophobic acrylic lenses (20). An important conclusion from this study was made that the straylight proportionally depends on the glistening number despite the differences of IOL material. (20). DeHoog et al. reported similar findings that a significant decrease of MTF values depended on the size and density of glistening, not on IOLs material (40).

As more studies used light scattering and straylight measurements, straylight became a reliable indicator for assessing the quality of vision (52). Miyata $e t$ al. found that light scattering on the anterior and posterior surfaces of the AcrySof IOL increased during the years (53). They did not find the significant correlation between the increased surface light scattering and changes in visual acuity, however, there were more cases with decreased visual acuity when the light scattering exceeded higher values (53).

The majority of the studies did not find significant subsurface nanoglistening impact on visual acuity, although it can increase light scattering significantly $(43,54,55)$. Werner et al. found that nanoglistening increased the light scatter and straylight, however, straylight levels were below the value of straylight hindrance $[1.47 \log (\mathrm{s})]$, leading to the conclusion that they were not able to cause significant and noticeable visual impairment (54).

Although recent studies showed that glistening could cause a significant increase of straylight and glare, straylight measurements cannot be compared to visual acuity or contrast sensitivity as these were identified as independent metrics $(52,56)$. Contrary to that, Alarcon et al. found that the MTF, which is used for the preclinical optical performance of IOL, correlated well with clinical data, including visual acuity and contrast sensitivity (57). Weindler et al. performed a study to evaluate the optical quality of hydrophobic acrylic IOLs with glistening (52). They used a classification based on the glistening number per $\mathrm{mm}^{2}$ : grade 0 (none), grade 1 (1 to 100 ), grade 2 (101 to
200), grade 3 (201 to 500), and grade 4 (more than 500) (52). The authors reported that a low number of glistening $(<500$ microvacuoles $/ \mathrm{mm}^{2}$ ) did not affect the optical quality of IOLs, but grade 4 glistening had significantly deteriorated MTF and Strehl ratio. However, they were evaluated as small (52). The reported results showed that even severe glistening had minimal impact on MTF values, suggesting that the visual acuity remains unaffected (52).

Son et al. performed a study to analyze different types of IOLs by assessing ray propagation while using their proposed visualization technique (58). The authors confirmed that the ray propagation could be visualized qualitatively and assessed quantitatively in different IOL models by using the proposed imaging technique (58). Moreover, they found that the image quality of IOLs also depends on light energy distribution (58).

\section{Calcifications}

Calcification occurs as the deposits of calcium phosphate accumulate in various bioprosthetic or biomaterial implants, including IOL, in the human body (1). Neuhann et al. suggested three main groups of calcifications: primaryrelated to IOL itself (properties of the polymer, it's surface or IOL packaging), the secondary calcification can occur as a result of diseases or pathologies that causes the disruption of $\mathrm{BAB}$ and pseudocalcification when false positive staining of calcium occurs (59). However, usually, calcification is a multifactorial problem (60). It appears as the surface irregularity in the central part of the optic or distributes over different parts of the IOL (61) (Figures 3,4). Postoperative IOL's calcification can look similar to the posterior capsule opacification (14). Nd:YAG laser treatment or mechanical scraping is usually ineffective, because most often deposits lie within the IOL material (62). IOL exchange due to the calcification can be the only possible method to restore reduced visual acuity, however, IOL explantation is associated with higher intraoperative complication rate (62). Dagres et al. reported such complications as zonular dehiscence, posterior capsular rupture, and corneal decompensation, which were related with IOL exchange surgery in $48 \%$ of cases with opacified IOLs (63). Unnecessary Nd:YAG laser capsulotomy in eyes with opacified IOLs may also increase the complication rate during the IOL's exchange procedure (64). It was reported that $33 \%$ of IOL exchanges require an anterior vitrectomy, this can increase to $48 \%$ with a previously performed Nd:YAG capsulotomy (65). 


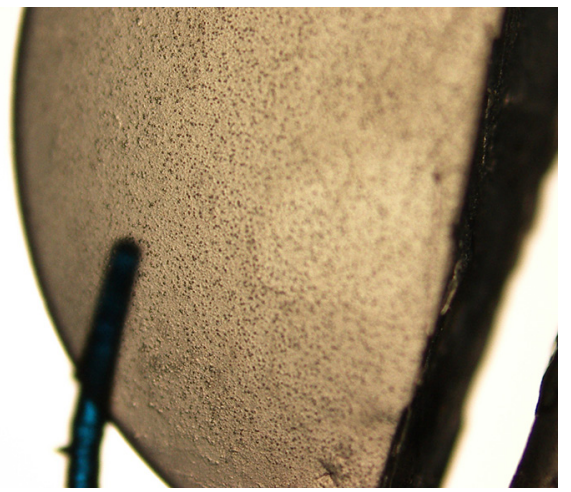

Figure 3 Light photomicrograph of a MemoryLens IOL (CibaVision) explanted because of calcification $(\times 40)$. Courtesy: Liliana Werner, MD, PhD, University of Utah.

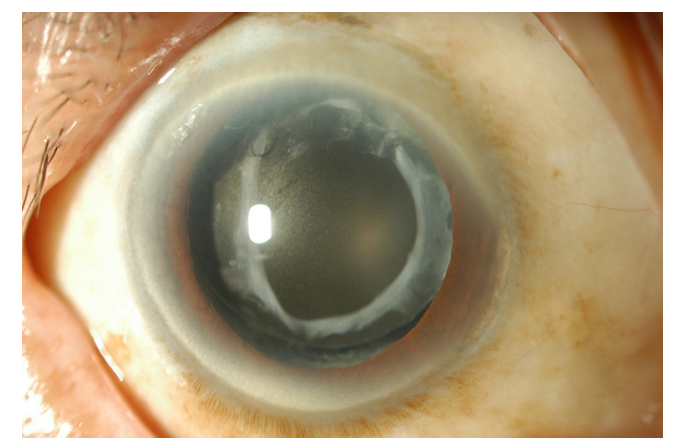

Figure 4 Calcification of the implanted IOL. Courtesy: Hiroyuki Matsushima, MD, PhD, Dokkyo Medical University.

The anterior segment optical coherence tomography (AS-OCT) was reported to be a reliable method to assess the presence, location and density of IOL's changes, including calcification, however, very superficial changes could not be detected $(10,66)$.

The majority of the studies reported IOL calcification more commonly in hydrophilic acrylic IOLs $(1,62,67)$. Choudhry et al. described two types of hydrophilic acrylic IOLs calcification: first consists of calcium precipitates on the IOL surfaces. In contrast, the second type includes granular calcium deposits within the substance of the IOL optic, beneath the anterior surface and in front of the posterior surface of the lens optic, the haptics and the edge of the optic (66).

Several studies evaluated secondary calcifications, i.e. calcifications related with other diseases, pathologies or specific intraoperative procedures. Although Ma et al. reported calcification of hydrophobic acrylic IOL after pars plana vitrectomy (PPV) with silicone oil tamponade, the patient had diabetes mellitus, that could cause the breakdown of $\mathrm{BAB}$ as mentioned above, and it was a single case (68). Few studies showed that the hydrophobic surface of hydrophilic acrylic IOLs does not protect them from the development of calcification because it initiates from the hydrophilic subsurface $(14,15)$.

Studies performed during the last decade indicated that there is a tendency of centrally localized IOL calcification, that is restricted to the pupillary or capsulorhexis area. This type of calcification occurred after posterior lamellar keratoplasty: Descemet-stripping automated endothelial keratoplasty (DSAEK), Descemet membrane endothelial keratoplasty (DMEK), and pars plana vitrectomy (PPV), with the intraocular injection of gas or air $(51,62)$. It was reported that direct air or gas contact with the IOL's surface increases the risk of hydrophilic IOLs opacification (51). However, the incidence of calcification is very low, after DMEK and DSAEK vary between 2.5-5\% (51,69,70).

Werner et al. proposed possible causes of calcification after surgeries that require exogenous gas or other substances injection into the eye (60). Injected gas, air, tissue plasminogen activator, silicone oil can have direct contact to IOL surface. Secondly, it can be related to a metabolic change in the anterior chamber due to the presence of the exogenous substance and lastly-exacerbated inflammatory reaction with the breakdown of $\mathrm{BAB}$ caused by the surgical procedure itself $(1,60)$.

The authors also reported that there is no association between this distinctive calcification localization and IOL design or manufacturer (60). A similar conclusion was made by Giers et al., who conducted a study of 11 cases of explanted hydrophilic IOLs with calcification from 4 different manufacturers after DMEK or DSAEK. The authors suggested that calcification occurs irrespective of the manufacturer or the exact composition of the hydrophilic lens material (71).

Most of the single case reports presented calcification of hydrophilic IOLs after DMEK, DSAEK (72-75). It is important to note that all these cases, except the report by Lee, had a somehow complicated postoperative course that led to repeated or different types of surgeries, suggesting that breakdown of $\mathrm{BAB}$ during surgeries might also influence the calcification process (68). Lee reported a case when the patient needed the rebulbing after DSAEK (74). It was reported in two studies that rebubbling after DSAEK and DMEK significantly elevates the risk of the development of IOL's calcification $(69,76)$. It was proposed 
that elevated IOP after the injection of intracameral air might also be a risk factor of the calcification process $(76,77)$. Although Ahad et al. observed the reduction of the opacification rate after reducing the time of high-pressure (IOP higher than $40 \mathrm{mmHg}$ ) air tamponade from $1 \mathrm{~h}$ to 10 $\mathrm{min}$, they did not get any statistically significant data (76).

Similar cases of centrally localized IOLs calcification after PPV with intraocular gas/air injection were more commonly observed in recent years. It was reported by Werner $e t a l$. that the possible cause of centrally localized calcification of anterior IOLs surface can be the migration of gas or silicone oil into the anterior chamber via zonular fiber defects (60). Khurana et al. reported a single case of anterior surface calcification of a hydrophilic acrylic IOL when the exposure of air in the anterior chamber was observed the next day after PPV (78). The authors proposed a possible mechanism (78). The exposure of gas to the IOL surface results in an increased hydrolyzation of the polyacrylate, forming free carboxylic acid groups that accumulate at the IOL surface triggering biomineralization, thereby covering the IOL optic with calcium phosphate deposits (78). These mechanisms could explain the fact that calcification was not seen in the IOL parts that were covered with the capsule $(62,78)$. However, some of the studies reported cases with no noticeable gas migration to the anterior chamber $(61,79)$. Likewise, the opacification of the posterior capsule was reported by Marcovich et al. (61). The authors performed a study with detected opacification in 11 hydrophilic acrylic IOLs produced by six different manufacturers, 1 month to 6 years after PPV involving the intravitreal gas injection (61). The authors hypothesized that the calcification might be caused by dehydration of the IOL due to slowly dissolving gas (61). The dehydration may induce chemical alterations on the IOL surface, causing deposition of calcium and phosphate from the aqueous humor in the exposed areas (61). Yildirim et al. performed a study with one of the most extensive series of confirmed calcification in 10 explanted hydrophilic acrylic IOLs after PPV with intraocular gas injection (62). They found that calcification was not present only on the surface of the IOL but up to $100 \mu \mathrm{m}$ within the material (62). In most of the cases, calcification was found in the anterior central pupillary area (62). The authors reported that there is a strong correlation between the density and size of the calcium deposits and the decrease in the IOL's optical quality $(47,62)$.

We found one study by Fung et al., who reported 7 cases of hydrophilic IOLs opacification after treatment with intracameral recombinant tissue plasminogen activator (rtPA) and hypothesized that rtPA possibly disrupts the $\mathrm{BAB}(80)$.

It is known that calcification in silicone IOLs is associated with the coexistence of asteroid hyalosis, as more than $85 \%$ of patients with calcification had clinically detectable ipsilateral asteroid hyalosis $(10,65,81,82)$. Calcification is thought to be caused by the same process as asteroid hyalosis because asteroid bodies are rich of calcium and phosphate, and it can occur despite the intact posterior capsule $(10,81)$. Espandar et al. reported three cases of silicone IOLs opacification in patients with asteroid hyalosis, who underwent Nd:YAG capsulotomy and that led to more chalengin IOLs exchange (81). Platt et al. proposed a possible method to remove calcified deposits from the posterior surface of IOL as the exchange of IOLs is associated with intraoperative and postoperative complications (65). The authors presented a surgical technique that included PPV, a lighted pick, and a modified silicone-tipped cannula with successful removal of late calcium deposition. However, it was a single case, and the follow-up was limited to 6 months (65).

Primary calcification is associated with the problems of IOL itself (59). It was reported that some of the different models of Oculentis IOLs, implanted between 2009 and 2012 , were affected by primary calcification because no other significant causes were found $(11,47)$. After the efforts to discover possible causes, the company concluded that its origin might be multifactorial and published few safety notifications $(11,47)$. Barra et al. performed a study with the same design hydrophilic Ioflex IOLs with calcification (67). They found the difference of light transmittance at a certain region in explanted and control IOLs, which had different expiration dates (67). The authors noted the importance of the manufacturing process evaluation because they found that different materials can be used or manufacturing processes can vary at a different time while manufacturing the same type of IOLs (67).

Yildirim et al. performed a study with nine segmented refractive bifocal Lentis MF IOLs, which were affected by primary calcification, as the granular deposits were found underneath the anterior and posterior surfaces distributed throughout the whole IOL, including the haptics (47). The authors reported that the density of calcium phosphate granules affected straylight significantly because the highest values were found in most severe cases (47). They did not find the correlation between light scattering and the MTF or visual acuity, suggesting that these are independent factors, and visual acuity may not be sufficient parameter to quantify the effect of IOLs' calcification (47). The similar 
results were reported by Łabuz et al. (51). A severe increase of straylight was caused by IOLs' calcification, which occurrence was associated with intraocular gas injection (51). However, the MTF values decreased just in two IOLs. These results were similar to other studies results, where MTF values did not show a significant effect too (51). The authors found a proportional relationship between the straylight parameter and the size and number of calcium deposits, suggesting that there is variability in the optical quality of affected IOLs (51). Tandogan et al. reported that MTF values deteriorated significantly in explanted Euromaxx ALI313Y and ALI313 IOLs with the calcification of the entire optic (64).

\section{Discussion}

We presented above main studies on IOL opacifications based on the review of recent literature. The summary of major recent original papers on glistenings is presented in Table 1 and on calcifications in Table 2. In this section we discuss two important and controversial issues related to IOL opacifications, which are risk factors and impact on visual quality.

It is known that the material of IOL plays an important role in opacification formation. Glistenings occurred more in hydrophobic IOLs and some of the studies observed it despite manufacturing changes $(34,82)$. However, Łabuz et al. showed that different hydrophobic materials differ in their resistance to the glistening formation (20). One of the possible causes is the difference of water content, as it was reported that certain hydrophobic IOLs with higher than ordinary water content was glistening free or its amount was showed to be very low (23). It was proposed that the higher refractive power of IOL can be associated with higher severity of glistenings. However, we found three studies $(44,46,83)$ that did not find the significant association between the IOLs power and the severity of glistenings and previously reported findings could be caused by the higher thickness of the material $(24,42,45)$.

Two long follow up studies showed that a higher amount of glistenings formed in AcrySof IOLs than in ZCBOO IOLs, likewise the anterior capsule opacification and fibrosis was more seen in AcrySof IOLs $(8,19)$. It was suggested that glistenings formation might be associated with the occurrence of anterior capsule opacification and tightness of the capsular bag (1). However, the authors did not perform analysis to evaluate this possible association, and they reported it as an observation. It is also known that glistenings tend to occur more often in AcrySof IOLs than in other hydrophobic IOLs.

One of the most important factors in the development of opacifications: glistenings and calcification, despite the properties of IOL, is the breakdown of $\mathrm{BAB}$, which modifies the aqueous humor composition (3). It is known to be disrupted in diabetes mellitus, and it was the main systemic disease associated with opacification formation $(12,45)$.

The significant association between glistenings formation and glaucoma was reported, as the daily use of topical glaucoma medications may lead to the rupture of BAB (41). Although Godlewska et al. did not find a statistically significant difference, they observed that glistenings formation was more frequent in glaucoma patients when compared to subjects without glaucoma (45). The breakdown of $\mathrm{BAB}$ can result in uveitis, and it was linked to glistenings formation. We found only one study which assessed patients with uveitis, however, the authors reported that they received high intensity steroid therapy, and the results showed statistically lower severity of glistenings in these patients (45).

The majority of the IOLs with confirmed calcification were hydrophilic in the reviewed studies. However, few cases of calcification in hydrophobic acrylic IOLs were reported, likewise, calcification was observed in silicone IOLs in association with the asteroid hyalosis, suggesting that calcification is not the problem only of hydrophilic IOLs $(10,65,68,69,81)$.

Complex or prolonged surgery and postoperative inflammation can lead to the breakdown of BAB, and that may induce glistening and calcification formation in the IOLs $(1,68,73,75)$. Although Gurabardhi et al. did not find a statistical correlation between ocular or systemic comorbidities and primary calcification, they found that diabetes, uveitis, and glaucoma were the most frequent pathologies (11). Although the incidence of IOLs calcification is low and studies evaluated not more than fifteen IOLs explanted due to the secondary calcification, it showed a significant effect of intraocular injection of exogenous air or gas on calcification formation as well as on the tendency of central localization. The main surgeries that required intraocular gas, air or silicone (86) injection were DSEK, DSAEK, DMEK, and PPV. The rebubbling after DSAEK and DMEK was reported as a significant risk factor for the development of IOL's calcification. The summary of risk factors for IOL glistenings and calcifications is presented in Table 3.

The early controversy related with the influence of IOL 
Table 1 The summary of major original studies on glistenings

\begin{tabular}{|c|c|c|c|}
\hline Authors & IOLs/patients & Evaluated parameters/methodology & Results \\
\hline \multirow{3}{*}{$\begin{array}{l}\text { Matsushima } \\
\text { et al. (12) }\end{array}$} & 5 explanted IOLs were MA60BM (Alcon) & VA was assessed & Light transmittance of the IOLs explanted from cases $1,2,3,4$ and 5 was $85.0 \%, 78.2 \%, 79.1 \% 80.1 \%$ and $76.7 \%$ (respectively) \\
\hline & Unimplanted MA60BM (Alcon) was used as control & Light transmission was measured by a double beam spectrophotometer & Compared with the light transmittance of a control unused IOL of $88.9 \%$; these values represent a decrease of from $4.4 \%$ to $13.7 \%$ \\
\hline & $\begin{array}{l}\text { Original implantation had occurred over a range of 6-15 } \\
\text { years prior to the IOL exchange }\end{array}$ & & All patients VA improved when IOLs were exchanged \\
\hline & 5 Santen Eternity Natural Uni NW-60 IOLs & Straylight was assessed & Median glistenings diameter was $23.8 \mu \mathrm{m}$ (AcrySoff) and $32.8 \mu \mathrm{m}$ (Eternity) \\
\hline & All IOLs had same dioptric power (+20.0 D) & & $\begin{array}{l}\text { Four (80\%) of the Acrysof lenses had straylight values higher than a } 20 \text {-year-old CIE standard glare observer and in two cases the } \\
\text { straylight exceeded that of the } 70 \text {-year-old CIE standard glare observer }\end{array}$ \\
\hline & & & None of the Eternity lenses had straylight values that exceeded the value for the 20-year-old CIE standard glare observer \\
\hline \multirow[t]{5}{*}{$\begin{array}{l}\text { Weindler } \\
\text { et al. (52) }\end{array}$} & $\begin{array}{l}38 \text { monofocal hydrophobic acrylic + } 21.0 \text { D AcrySof SA60AT } \\
\text { IOLs }\end{array}$ & Glistenings were induced in vitro & The mean glistening diameter in grades 1 through 4 IOLs was $15.31 \pm 3.13 \mathrm{~mm}$ (range, 7.33 to $24.74 \mathrm{~mm}$ ). \\
\hline & Control group of 20 IOLs & A classification was applied based on the glistening number per $\mathrm{mm}^{2}$ & The mean glistening numbers $\pm S D\left(M V / \mathrm{mm}^{2}\right)$ in grades 1 through 4 were $74 \pm 12.7,142 \pm 22.2,297 \pm 76.2$, and 1,509 \pm 311.9 , respectively. \\
\hline & & MTF and Strehl ratio was assessed & The mean glistening sizes in grades 1 through 4 were $13.28 \pm 3.85,15.88 \pm 2.08,16.85 \pm 3.23$, and $15.27 \pm 2.25 \mathrm{~mm}$, respectively. \\
\hline & & & Glistening grades 1 through 3 did not change the optical quality \\
\hline & & & In grade 4, the MTF and the Strehl ratio were significantly affected, however the effects found were small and are unlikely to affect the VA \\
\hline \multirow[t]{2}{*}{ Son et al. (58) } & $\begin{array}{l}4 \text { IOLs: a monofocal AcrySof IQ SN60WF (Alcon); diffractive- } \\
\text { refractive bifocal AcrySof IQ Restor SN6AD1 (Alcon); } \\
\text { diffractive trifocal AcrySof IQ PanOptix TFNTOO (Alcon); } \\
\text { diffractive extended-depth-of-focus (EDOF) Symfony ZXRo0 } \\
\text { (Johnson \& Johnson) }\end{array}$ & $\begin{array}{l}\text { An experimental set-up with a water bath containing } 0.01 \% \text { fluorescein solution and } \\
\text { monochromatic green laser light }(532 \mathrm{~nm}) \text { was used }\end{array}$ & Both the diffractive-refractive bifocal IOL and the EDOF IOL showed two defined foci for distance and near vision \\
\hline & All studied lenses power was $+21.0 \mathrm{D}$ & MTF and Through-Focus Response was assessed & In the diffractive trifocal IOL, three distinct foci for distance, intermediate, and near vision could be visualized \\
\hline & $\begin{array}{l}\text { SN60WF(Alcon), MA60AC (Alcon); Aktis SP NS; YG (Nidek); } \\
\text { Avansee (Kowa) }\end{array}$ & Straylight was assessed & The mean size of glistenings ranged from 5.2 to $10.2 \mu \mathrm{m}$ \\
\hline & & & The highest density of glistenings was found in the PY-60D IOLs ranging from 3,058 to $4,061 \mathrm{MV} / \mathrm{mm}^{2}$ \\
\hline & & & MAGOAC samples demonstrated the largest size of glistenings \\
\hline & & & The mean straylight parameter $\left( \pm \mathrm{SD}\right.$ ) of the IOLs prior incubation ranged from 0.1 to $1.3 \mathrm{deg}^{2} / \mathrm{sr}$ \\
\hline & & & $\begin{array}{l}\text { Straylight of the CT Lucia was } 1.09 \pm 0.99 \mathrm{deg}^{2} / \mathrm{sr} \text {, PY-60AD it was } 19.30 \pm 2.07 \mathrm{deg}^{2} / \mathrm{sr} \text {, for the SN60WF and MA60AC IOLs it was } \\
1.15 \pm 0.15 \mathrm{deg}^{2} / \mathrm{sr} \text { and } 5.95 \pm 3.67 \mathrm{deg}^{2} / \mathrm{sr}_{\mathrm{r}} \text { respectively, for the Aktis it was } 1.71 \pm 0.84 \mathrm{deg}^{2} / \mathrm{sr} \text {, for the Avansee it was } 0.95 \pm 0.24 \mathrm{deg}^{2} / \mathrm{sr}\end{array}$ \\
\hline \multirow{6}{*}{$\begin{array}{l}\text { Łabuz } \\
\text { et al. (21) }\end{array}$} & 47 monofocal IOLs & IOLs extracted from donor pseudophakic eyes & The mean straylight at 2.5 degrees and 7.0 degrees was $5.78 \mathrm{deg}^{2} / \mathrm{sr} \pm 4.70$ and $5.06 \pm 4.01 \mathrm{deg}^{2} / \mathrm{sr}$, respectively \\
\hline & & Straylight was assessed at a 2.5-degree and 7.0-degree scatter angle, results were & 30 of the 74 IOLs $(41 \%)$ straylight was below the level of that of the 20 -year-old crystalline lens \\
\hline & & $\begin{array}{l}\text { compared with the straylight of a } 20 \text {-year-old crystalline lens, a } 70 \text {-year-old crystalline } \\
\text { lens and a lens with cataract }\end{array}$ & Straylight was above the level of the 70 -year-old crystalline lens in 10 IOLs (14\%) \\
\hline & & & None showed a straylight level close to that of the cataractous lens \\
\hline & & & Increased straylight was associated with surface deposits, snowflake-like degeneration, and glistenings \\
\hline & & & 34 IOLs (43\%) were free of IOL pathology; 40 IOLs showed different levels of opacification \\
\hline \multirow{4}{*}{$\begin{array}{l}\text { Łabuz et al. } \\
\text { (38) }\end{array}$} & 7 AcrySof IOLs: 5 SN6OWF; 2 SN60AT & Glistenings were induced in vitro & The median size of glistenings in was $5.4 \pm 2.7 \mathrm{~mm}$ (range, 4.6 to $12.5 \mathrm{~mm}$ ) \\
\hline & & Straylight was assessed & The number of induced glistenings ranged from 114 to 12386 per mm², the surface portion ranged from $1.4 \%$ to $26.9 \%$ \\
\hline & & & At 2.5 degrees, the range in the straylight parameter was 1.49 to $72.49 \mathrm{deg}^{2} / \mathrm{sr}$; at 7.0 degrees, it was 1.72 to $62.87 \mathrm{deg}^{2} / \mathrm{sr}$ \\
\hline & & & Straylight was proportionally related to the total number of glistenings and the surface portion \\
\hline
\end{tabular}

Table 1 (Continued) 
Table 1 (Continued)

\begin{tabular}{|c|c|c|c|}
\hline Authors & IOLs/patients & Evaluated parameters/methodology & Results \\
\hline \multirow[t]{4}{*}{$\begin{array}{l}\text { Henriksen } \\
\text { et al. (39) }\end{array}$} & $\begin{array}{l}79 \text { pseudophakic patients with visual acuity no worse than } \\
0.02 \text { logMAR and no ocular pathology were enrolled }\end{array}$ & All IOLs were photographed, and glistenings were analyzed for size and density & All 79 patients had glistenings within 2 diameter groups: 6 to $25 \mu \mathrm{m}$ and over $25 \mu \mathrm{m}$ \\
\hline & \multirow{3}{*}{$\begin{array}{l}\text { The SN60WF IOL was implanted in } 36 \text { eyes ( } 45.5 \%) \text {, the } \\
\text { SN60AT in } 36 \text { eyes }(45.5 \%) \text {, the SN60T5 in } 4 \text { eyes (5.2\%), } \\
\text { the SN60T4 in } 1 \text { eye ( }(1.3 \%) \text {, the SN60T3 in } 1 \text { eye }(1.3 \%) \text {, } \\
\text { and the SNG6AD3 in } 1 \text { eye (1.3\%) }\end{array}$} & \multirow{3}{*}{$\begin{array}{l}\text { Outcome measures included logMAR CDVA, mesopic } 10 \% \text { contrast logMAR CDVA } \\
\text { with and without glare, and straylight determination with a straylight meter (C Quant } \\
\text { log) }\end{array}$} & Linear regression for the non-stratified group was significant for IOL glistening size vs. contrast VA with glare \\
\hline & & & $\begin{array}{l}\text { Linear regression for the } 6 \text { to } 25 \mu m \text { group was significant for a measure of severity index (\%area) vs. the straylight meter measurements, } \\
\text { \%area/size vs. straylight meter measurements, IOL age vs. CDVA, IOL age vs. contrast VA, and IOL age vs. contrast VA with glare }\end{array}$ \\
\hline & & & $\begin{array}{l}\text { Linear regression for the over } 25 \text { um group was significant for IOL age vs. glistening size and \%area/size vs. contrast VA, and density vs. } \\
\text { CDVA and contrast VA with glare }\end{array}$ \\
\hline \multirow[t]{2}{*}{$\begin{array}{l}\text { Werner et al. } \\
\text { (23) }\end{array}$} & $\begin{array}{l}\text { IOLs types: Clareon CNAOTO, Tecnis ZCBO0 and Tecnis } \\
\text { OptiBlue ZCBOoV, Eternity W-60, enVista MX60, and Vivinex } \\
\text { XY1 }\end{array}$ & Glistenings were induced in vitro & $\begin{array}{l}\text { The surface haze }(\mathrm{n}=10, \mathrm{PIU}) \text { was } 4.25 \pm 0.87 \text { (CNA0T0), } 9.50 \pm 1.66(\mathrm{ZCBO} 00), 39.48 \pm 1.97(\mathrm{ZCBO} 00 \mathrm{~V}), 46.68 \pm 3.16(\mathrm{~W}-60), 44.70 \pm 4.00(\mathrm{MX} 60) \text {, } \\
\text { and } 4.42 \pm 0.71(\mathrm{YY} 1)(\mathrm{P}<0.001) \text {, which showed a strong correlation with surface roughness measurements }(\mathrm{R}=0.94, \mathrm{P}=0.006)\end{array}$ \\
\hline & For surface haze 10 IOLs from each group were used & Scheimpflug densitometry was used & The glistenings density $(\mathrm{n}=30$ ) was the lowest for the CNAOTO, W- 60 , and MX60 IOLs \\
\hline \multirow{4}{*}{$\begin{array}{l}\text { Rønbeck et al. } \\
\text { (27) }\end{array}$} & \multirow{4}{*}{$\begin{array}{l}46 \text { patients with PMMA, silicone and hydrophobic acrylic } \\
\text { IOLs }\end{array}$} & \multirow[t]{4}{*}{ Scheimpflug imaging and an image analysis program was used } & The median follow-up time postoperatively was 12.2 years (range, 11.3-13.4) \\
\hline & & & The hydrophobic acrylic IOL had significantly more lens glistenings than the silicone $(P=0.003)$ and the PMMA $(P=0.000)$ IOLs \\
\hline & & & The silicone IOL had significantly more lens glistenings than the PMMA lens $(P=0.048)$ \\
\hline & & & The IOL power did not affect the degree of lens glistenings in the hydrophobic acrylic IOL group $(P=0.64)$ \\
\hline \multirow{5}{*}{$\begin{array}{l}\text { Colin et al. } \\
\text { (34) }\end{array}$} & \multirow[t]{5}{*}{111 eyes with blue light-filtering AcrySof SN6OWF IOLs } & \multirow{5}{*}{$\begin{array}{l}\text { The incidence and severity of glistenings were evaluated with the slitlamp } \\
\text { Glistenings were subjectively graded ( } 0=\text { absent; } 1=\text { moderate; } 2=\text { dense) }\end{array}$} & Glistenings occurred in 96 eyes (86.5\%) \\
\hline & & & Glistenings were of grade 1 severity in 45 eyes $(40.5 \%)$ and of grade 2 severity in 51 eyes $(45.9 \%)$ \\
\hline & & & The follow-up was significantly longer in eyes with grade 2 glistenings $(P \leq 0.01)$ \\
\hline & & & A limited, but significant, correlation was found between glistening severity and length of follow-up $(r=0.32, P<0.01)$ \\
\hline & & & $\begin{array}{l}\text { Although there was a trend toward decreased VA at higher glistening grades, there were no significant differences in CDVA between the } \\
\text { glistening severity groups }\end{array}$ \\
\hline \multirow[t]{4}{*}{$\begin{array}{l}\text { Kahraman } \\
\text { et al. (19) }\end{array}$} & \multirow{4}{*}{$\begin{array}{l}50 \text { eyes of } 25 \text { patients. Patients had an AcrySof SA60AT IOL } \\
\text { (Group A) implanted in } 1 \text { eye and a Tecnis ZCBOO IOL (Group } \\
\text { B) implanted in the fellow eye }\end{array}$} & $\begin{array}{l}\text { At } 1,3 \text {, and } 5 \text { years, the PCO level was evaluated with the Evaluation of Posterior } \\
\text { Capsule Opacification software }\end{array}$ & $\begin{array}{l}\text { No significant differences in } P C O \text { scores were found between the } 2 \text { groups at all follow-up visits [1 year: } 0.06 \pm 0.12 \text { (SD) vs. } 0.07 \pm 0.13 \text {, } \\
P=0.35 ; 3 \text { years: } 0.23 \pm 0.36 \text { vs. } 0.22 \pm 0.32, P=0.66 ; 5 \text { years: } 0.36 \pm 0.41 \text { vs. } 0.36 \pm 0.54, P=0.98]\end{array}$ \\
\hline & & The level of ACO and capsule retraction was graded subjectively & A significant increase in $\mathrm{PCO}$ score was found between 3 and 5 years $(\mathrm{P}<0.01)$ \\
\hline & & Glistenings were scored as present or not present & $\begin{array}{l}\text { ACO was present in Group A and Group B in } 18.0 \% \text { and } 2.7 \% \text { of eyes }(P=0.03) \text {, in } 92.0 \% \text { and } 24.0 \% \text { of eyes, and in } 100 \% \text { and } 52 \% \text { of } \\
\text { eyes }(P<0.01) \text { at } 1,3 \text {, and } 5 \text { years, respectively }\end{array}$ \\
\hline & & & Glistenings [ 1 year, 33 eyes (66.0\%); 3 years, 43 eyes (86.0\%); 5 years, 25 eyes $(100 \%)]$ were only observed in Group A \\
\hline \multirow[t]{5}{*}{$\begin{array}{l}\text { Johansson } \\
\text { et al. (8) }\end{array}$} & \multirow{5}{*}{$\begin{array}{l}50 \text { cataract patients received either an AcrySof IQ SN6oWF } \\
\text { (Alcon, Fort Worth, TX, USA) or a Tecnis ZCBOO (Abbott } \\
\text { Medical Optics, Santa Ana, CA, USA) IOL in the first } \\
\text { operated eye, and the second eye received the IOL type not } \\
\text { implanted in the first eye }\end{array}$} & $\begin{array}{l}\mathrm{ACO} \text { and } \mathrm{PCO} \text { and fibrosis were monitored with slitlamp photography and } \\
\text { semiautomated digital analysis } 2 \text { and } 3 \text { years postoperatively }\end{array}$ & Visual outcomes were similar for the two IOLs \\
\hline & & \multirow[t]{4}{*}{ Glistenings were assessed in slitlamp photographs } & Anterior capsular fibrosis and opacification developed more often in SN6OWF eyes \\
\hline & & & $\begin{array}{l}\text { Mean PCO area percentage was larger in ZCBO0 eyes } 3 \text { years after surgery, but severity score did not differ with statistical significance } \\
\text { between the two IOLs }\end{array}$ \\
\hline & & & $\begin{array}{l}\text { Six ZCBO0 eyes and } 2 \text { SN60WF eyes underwent Nd:YAG laser treatment during a mean of } 4 \text { years } 8 \text { months after surgery. This difference } \\
\text { was not statistically significant. }\end{array}$ \\
\hline & & & A high amount of glistenings developed in most SN6OWF IOLs, while only few ZCBO0 IOLs displayed a low degree of glistenings \\
\hline
\end{tabular}


Table 1 (Continued)

\begin{tabular}{|c|c|c|c|}
\hline Authors & IOLs/patients & Evaluated parameters/methodology & Results \\
\hline \multirow[t]{3}{*}{$\begin{array}{l}\text { Chang et al. } \\
\text { (83) }\end{array}$} & \multirow[t]{3}{*}{$\begin{array}{l}80 \text { patients: } 40 \text { AcrySof SA60AT (1-piece IOL group); } 40 \text { a } \\
\text { Sensar AR40e (3-piece IOL group) }\end{array}$} & $\begin{array}{l}5 \text { to } 7 \text { years postoperatively, retroillumination images were obtained and the PCO } \\
\text { area and severity were evaluated using computer software }\end{array}$ & There were no significant differences in PCO between the 2 groups \\
\hline & & High-contrast $(100 \%)$ and low-contrast $(2.5 \%)$ CDVA were measured & The 3-piece IOL group had significantly fewer glistenings $(P<0.001)$ \\
\hline & & $\begin{array}{l}\text { Scheimpflug images were obtained to evaluate glistenings, which were quantified } \\
\text { objectively by digital image analysis using computer software }\end{array}$ & $\begin{array}{l}\text { There was correlation between the subjective grading of glistenings and objective computer-processed image grading } \\
\text { The glistenings were not correlated with IOL power, CDVA, or CS }\end{array}$ \\
\hline \multirow[t]{4}{*}{$\begin{array}{l}\text { Thomes et al. } \\
\text { (82) }\end{array}$} & $\begin{array}{l}\text { AcrySof Natural IOLs Model SB30 AL ( } n=100) \text { manufactured } \\
\text { in } 2003\end{array}$ & Glistenings were induced in vitro & Glistenings were present in all lenses after the accelerated microvacuole test method \\
\hline & \multirow[t]{3}{*}{$\begin{array}{l}\text { AcrySof Natural IQ Model SN60 WF IOLs ( } \mathrm{n}=270) \\
\text { manufactured in } 2012\end{array}$} & \multirow[t]{3}{*}{ Image analysis program was used to evaluate glistenings } & $\begin{array}{l}\text { The mean microvacuole density for IOLs manufactured in } 2003 \text { was } 315.7 \text { microvacuoles per square millimeter (MVs/mm²) with a } \\
\text { glistening severity less than } 100 \mathrm{MVs} / \mathrm{mm}^{2} \text { in } 1.0 \% \text { of the } 10 \mathrm{Ls}\end{array}$ \\
\hline & & & $\begin{array}{l}\text { The mean microvacuole density for IOLs manufactured in } 2012 \text { was } 39.9 \mathrm{MVs} / \mathrm{mm}^{2} \text { with a glistening severity less than } 100 \mathrm{MVs} / \mathrm{mm}^{2} \text { in } \\
95.2 \% \text { of the IOLs }\end{array}$ \\
\hline & & & $\begin{array}{l}\left.\text { Laboratory-induced microvacuole density was significantly lower in IOLs manufactured in } 2012 \text { (mean } 39.9 \mathrm{MVs} / \mathrm{mm}^{2}\right) \text { relative to IOLs } \\
\text { manufactured in } 2003 \text { (mean } 315.7 \mathrm{MVs} / \mathrm{mm}^{2} \text { ) as indicated by the Wilcoxon test of significance }(P<0.0005)\end{array}$ \\
\hline \multirow[t]{2}{*}{$\begin{array}{l}\text { Miyata et al. } \\
\text { (35) }\end{array}$} & $\begin{array}{l}24 \text { eyes received AcrySof SN6OWF IOL before } \\
\text { manufacturing improvement }\end{array}$ & $\begin{array}{l}\text { Light scattering on the anterior IOL surface was examined up to } 3 \text { years } \\
\text { postoperatively using an EAS-1000 anterior segment analyzer }\end{array}$ & $\begin{array}{l}\text { After the improvement, the IOLs showed no increase in surface light scattering up to } 2 \text { years, a significant increase was found at } 3 \text { years } \\
(P<0.001)\end{array}$ \\
\hline & 27 eyes received AcrySof SN60WF IOL after improvement & $\begin{array}{l}\text { The CDVA and CS under photopic and mesopic conditions were also examined } 3 \\
\text { years postoperatively }\end{array}$ & $\begin{array}{l}\text { The light scattering with the improved IOL was significantly reduced at all observations }(P<0.048) \\
\text { No difference was found in the CDVA and CS }\end{array}$ \\
\hline \multirow{5}{*}{$\begin{array}{l}\text { van der } \\
\text { Mooren et al. } \\
\text { (84) }\end{array}$} & $\begin{array}{l}5 \text { AcrySof IOLs (Alcon Laboratories Inc, Forth Worth, Texas, } \\
\text { USA) }\end{array}$ & Glistenings were induced in vitro. & $\begin{array}{l}\text { The number of microvacuoles per cubic } \mathrm{mm} \text { in AcrySof lenses ranged from } 46 \text { to 3,862; iSymm IOLs ranged from 2,545 to 6,495; enVista } \\
\text { IOLs } 3 \text { to 6; Tecnis lenses ranged from } 12 \text { to } 36\end{array}$ \\
\hline & 3 iSymm IOLs (HOYA Surgical Optics Inc, Singapore), & $\begin{array}{l}\text { Microvacuole particle size distribution and particle volume density was measured } \\
\text { using confocal light microscopy and dark field microscopy, the corresponding } \\
\text { extinction coefficient } \gamma \text { was determined }\end{array}$ & $\begin{array}{l}\text { The MV in the enVista IOLs had an effective diameter of approximately } 33 \mu \mathrm{m} \text { and in the Tecnis IOLs } 25 \mu \mathrm{m} \text { while the sizes in the iSymm } \\
\text { IOLs and AcrySof IOLs were significantly smaller, } 5.2 \text { and } 6.2 \mu \mathrm{m} \text {, respectively }\end{array}$ \\
\hline & \multirow[t]{3}{*}{$\begin{array}{l}5 \text { Tecnis IOLs (Abbott Medical Optics Inc, Santa Ana, } \\
\text { California, USA) }\end{array}$} & A slitlamp image at a 45 degrees angle was taken & $\begin{array}{l}\text { The authors defined a lens with significant glistenings to be a lens that has microvacuoles such that it causes stray light levels to } \\
\text { be raised above those of a healthy } 20 \text {-year-old crystalline lens. This level of stray light is further specified as } \gamma \geq 0.08 \mathrm{~mm}^{-1} \text {, which } \\
\text { corresponds to } 4 \% \text { light scatter of the incident light beam }\end{array}$ \\
\hline & & $\begin{array}{l}\text { The ratio between the forward and backward scattered intensities for the } 45 \text { degrees } \\
\text { angle was calculated by using the MIEplot program }\end{array}$ & 3 iSymm IOLs and 4 of the 5 AcrySof IOLs were associated with significant glistenings \\
\hline & & Light transmittance was evaluated & \\
\hline \multirow{3}{*}{$\begin{array}{l}\text { DeHoog et al. } \\
(40)\end{array}$} & A pseudophakic eye model was created & \multirow{3}{*}{$\begin{array}{l}\text { The modeling and evaluation of scatter and MTF were performed for several } \\
\text { biomaterials with various size and density of glistenings under scotopic, mesopic, } \\
\text { and photopic conditions }\end{array}$} & Glistenings in IOLs lead to reduction in the MTF \\
\hline & \multirow{2}{*}{$\begin{array}{l}\text { Models of } 3 \text { IOL materials: PMMA, hydrophilic acrylic, and } \\
\text { hydrophobic acrylic were examined }\end{array}$} & & The relative \% MTFDrop had a nonlinear dependency on pupil size in all cases \\
\hline & & & $\begin{array}{l}\text { In most cases, the relative \% MTFDrop was inversely proportional to the size of glistenings and directly proportional to the density of } \\
\text { glistenings }\end{array}$ \\
\hline \multirow[t]{3}{*}{$\begin{array}{l}\text { Hayashi et al. } \\
\text { (16) }\end{array}$} & \multirow{3}{*}{$\begin{array}{l}35 \text { eyes that underwent implantation of a hydrophobic } \\
\text { acrylic, silicone, or PMMA IOL more than } 10 \text { years ago were } \\
\text { recruited }\end{array}$} & The scattering light intensity was measured using Scheimpflug photography & $\begin{array}{l}\text { Mean scattering light intensity of the surface and internal matrix of the optic was significantly higher in the acrylic group than in the } \\
\text { silicone and PMMA groups }(P<0.0001)\end{array}$ \\
\hline & & $\mathrm{VA}$, contrast VA, and glare VA were examined using a contrast sensitivity tester & $\begin{array}{l}\text { Mean uncorrected VA, photopic and mesopic contrast VA and glare VA, and HOAs did not differ significantly among groups, although } \\
\text { mean corrected VA in the acrylic group was significantly better than that in the other groups }(P=0.0023)\end{array}$ \\
\hline & & Ocular HOAs were measured using a Hartmann-Shack aberrometer & $\begin{array}{l}\text { Scattering light intensity of the surface and internal matrix did not correlate with VA, contrast VA, or glare VA, and did not correlate with } \\
\text { ocular and internal optic HOAs in the acrylic group }\end{array}$ \\
\hline
\end{tabular}

Table 1 (Continued) 
Table 1 (Continued)

\begin{tabular}{ll}
\hline Authors & \multicolumn{1}{c}{ IOLs/patients } \\
\hline $\begin{array}{l}\text { Schweitzer } \\
\text { et al. (41) }\end{array}$ & $\begin{array}{l}67 \text { glaucomatous eyes (47 patients), who previously had a } \\
\text { phacoemulsification with a hydrophobic acrylic IOL }\end{array}$
\end{tabular}

Evaluated parameters/methodology
All eyes underwent a BCVA evaluation, a complete clinical examination, a visual

Results

et al. (41) phacoemulsification with a hydrophobic acrylic IOL field test, CS evaluation and a wavefront analysis of HOAs using a Shack-Hartman

aberrometer

26 eyes (38.8\%) had a grade 0, 12 eyes (17.9\%) a grade 1 and 29 eyes (43.3\%) a grade 2 of glistening severity grade

Glistening was classified in three groups of severity grade: G0 ( $<50$ microvacuoles per $\left.\mathrm{mm}^{2}\right), \mathrm{G} 1$ (50-150 microvacuoles per $\left.\mathrm{mm}^{2}\right)$, and G2 (>150 microvacuoles per $\left.\mathrm{mm}^{2}\right)$

Ther

A higher number of topical glaucoma medication were associated with a higher glistening severity grade $(P<0.05)$

G1 and G2 groups had significantly lower mean CS values at high spatial frequencies and significantly higher loss variance values of the visual field test $(P<0.05)$

There was no significant difference in mean BCVA between groups $(P=0.455)$

Surface light scattering in the study group continued to increase up to 15 years postoperatively

The light scattering was higher on the anterior IOL surface after 4.5 years. Increased surface light scattering had no significant impact on CDVA; however, there were more cases with decreased CDVA when the surface light scattering exceeded 50 CCTU

Patients with the hydrophilic IOL had statistically significantly fewer glistenings $(P<0.001)$

The development of glistenings was not correlated with IOL power, CDVA, or CS

There was no statistical correlation between glistening grades and patients' age, IOLs power, postoperative UCVA and BCVA $(P>0.05)$ Quantificationally, CS values among each group were not statistically different

Qualitative analysis showed there were more eyes in grade 3 group than in grade 0 group having abnormally declined CS at high spatia frequency ( $10 \%$ vs. $36.7 \%$ at $18 \mathrm{cpd}, \mathrm{P}=0.029 ; 6.7 \%$ vs. $26.7 \%$ at $12 \mathrm{cpd}, \mathrm{P}=0.013$ )

Mean deviation of the visual field test was $-2.14 \pm 2.31,-1.97 \pm 2.23,-3.02 \pm 3.17,-4.12 \pm 3.38$ in group 0 to 3 respectively Mean MD value in patients of grade 3 was significantly higher than that in grade 0 and $1(P=0.008 ; P=0.005)$, although it was not higher than that in grade $2(P=0.138)$

No significant impact on visual function, BCVA and LCVA 10\% and 2.5\% in eyes with a more pronounced light scattering or a higher grade of glistenings seen at the slit-lamp was detected

The correlation between IOL dioptric power and both the total light scattering of the IOL, and the subjective grading of the intensity of the glistenings at the slit-lamp was statistically significant

The light scattering was measured by Scheimpflug photography

The degree of glistenings was quantified at the slitlamp The Complete Angle Scatter Instrument scatterometer was used to measure the

The MTF and Badal images were obtained

Backscatter was measured with a Scheimpflug camera (EAS-1000) and light

transmittance with a spectrophotometer (Lambda 35 UV-VIS)

FVA was assessed

\section{SSNG group comprised 19 eyes with AcrySof IOL} implanted more than 5 years ago

Control group of 20 eyes with AcrySof implanted between 6 Surface light scattering was assessed using Scheimpflug images months to 1 year

Beheregaray 42 eyes with SSNGs in AcrySof IOLs (study group)

Forward light scattering was assessed with a double-pass device using OSI as quantitative parameter

Backward light scattering was evaluated using Scheimpflug imaging (EAS-1000)

The CS function was assessed as the area under the log contrast sensitivity function (AULCSF) measured with the Optec 6500 devic The mean straylight values at a scattered angle of 10 degrees were $1.06 \pm 0.23 \log (s)$ for blue light-filtering $1 O L s, 0.97 \pm 0.28 \log (s)$ for $\operatorname{lOLs}$
without a blue-light filter, and $0.22 \pm 0.22 \log (\mathrm{s})$ for controls

The MTF and Badal image contrast of IOLs removed from cadaver eyes were similar to control values (no subsurface nanoglistenings). Backscatter was significantly higher in IOLs from cadaver eyes, although light transmittance was similar to that of controls

There were significant differences in visual maintenance $(\mathrm{P}=0.035)$ and standard deviation of visual acuity $(\mathrm{P}=0.031)$ between the two groups

No significant differences were found in baseline VA, FVA, maximum VA, minimum VA, and number of blinks

None of the FVA parameters showed any significant correlations with the intensity of surface light scattering, time after surgery, or age In the study group, logMAR CDVA ranged from -0.176 to $0.045(-0.06 \pm 0.07)$; no patient had a CDVA worse than 20/25

The OSI was significantly higher than in the control group ( $(\mathrm{P}=0.0074)$ and correlated with CDVA $(\mathrm{P}=0.0021)$, AULCSF photopic without glare $(P=0.0002)$ and with glare $(P<0.0001)$, and AULCSF mesopic without glare $(P=0.0038)$ and with glare $(P=0.0008)$

Multivariate analysis showed OSI was the only variable that correlated with CDVA and CS with glare

The OSI and age correlated with CS without glare $(\mathrm{P}<0.05)$

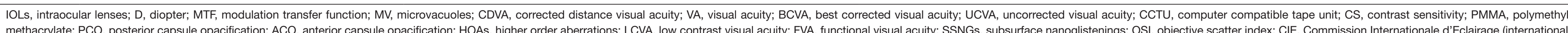

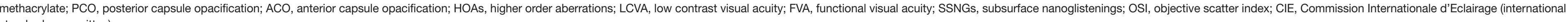
standards committee). 
Table 2 The summary of major original studies on calcification

\begin{tabular}{|c|c|c|c|}
\hline Authors & IOLs/Patients & Evaluated parameters/methodology & Results \\
\hline \multirow[t]{4}{*}{ Tandogan et al. (64) } & \multirow[t]{4}{*}{$\begin{array}{l}6 \text { explanted Euromaxx IOLs: } 5 \text { Euromaxx ALI313Y; } 1 \text { Euromaxx } \\
\text { ALI313 }\end{array}$} & X-ray spectroscopy & $\begin{array}{l}\text { Macroscopically, the entire optic was opacified in all IOLs. Numerous fine, granular, crystalline-like deposits, which were always distributed in a line } \\
\text { parallel to the anterior and posterior surfaces of the IOLs }\end{array}$ \\
\hline & & Light and scanning electron microscopy & X-ray spectroscopy could prove the deposits consisted of Calcium and Phosphate \\
\hline & & MTF was assessed & The MTF measurements of the IOLs with an intact optic (1 was not able to evaluate) showed a significant decrease in optical quality \\
\hline & & & $\begin{array}{l}\text { Measurements in the optical bench showed significant reduction of MTF values at all spatial frequencies and United States Air Force target pictures } \\
\text { demonstrated a significant reduction of brightness as well as resolution with the opacified IOLs }\end{array}$ \\
\hline \multirow[t]{4}{*}{ Barra et al. (67) } & 7 explanted loflex IOLs & AS-OCT was used & $\begin{array}{l}\text { The explanted IOLs demonstrated the presence of granular deposits, which were predominantly located on the surface/subsurface of the IOLs, } \\
\text { particularly the anterior surface }\end{array}$ \\
\hline & \multirow[t]{3}{*}{8 control loflex IOLs } & $\begin{array}{l}\text { Light scattering was measured with a Scheimpflug } \\
\text { camera }\end{array}$ & Light scattering was $219.71 \mathrm{CCT} \pm 2.62$ for explanted IOLs and $4.75 \pm 2.50 \mathrm{CCT}$ for controls \\
\hline & & \multirow{2}{*}{$\begin{array}{l}\text { Light transmittance was assessed with a } \\
\text { spectrophotometer }\end{array}$} & The mean light transmittance in the visible light spectrum was $75.94 \%$ to $87.25 \%$ for explanted IOLs and $97.54 \%$ to $98.97 \%$ for controls \\
\hline & & & $\begin{array}{l}\text { A variable degree of light transmittance between } 290 \mathrm{~nm} \text { and } 350 \mathrm{~nm} \text { (ultraviolet-A and B radiation) in the explanted and control IOLs with expiration } \\
\text { dates in 2009/2010 but } 0 \% \text { transmittance in this region in all controls with expiration dates in 2011/2012 }\end{array}$ \\
\hline \multirow{3}{*}{$\begin{array}{l}\text { Bompastor-Ramos } \\
\text { et al. (15) }\end{array}$} & 20 explanted opacified Lentis LS-502-1 (Oculentis GmbH) & Slitlamp examination & The mean interval between the initial cataract surgery and the diagnosis of opacification of the IOLs was $29.15 \pm 9.57$ months (range, 6 to 45 months) \\
\hline & \multirow[t]{2}{*}{ IOLs } & CDVA & $\begin{array}{l}\text { Opacification led to a statistically significant reduction in corrected distance visual acuity (mean 0.86 } \pm 0.76 \log M A R ; P<0.001 \text { ) and occurred in } 5.1 \% \\
\text { of the hydrophilic-hydrophobic acrylic IOLs implanted at the department }\end{array}$ \\
\hline & & & A yellowish diffuse opacification of the optic and haptics with no clear areas \\
\hline \multirow[t]{2}{*}{ Gartagnis et al. (14) } & \multirow{2}{*}{$\begin{array}{l}6 \text { hydrophilic acrylic IOLs (Lentis LS- 502-1) with a hydrophobic } \\
\text { surface }\end{array}$} & SEM and EDX & Two of the patients underwent combined pars-plana-vitrectomy and silicone oil instillation combined with phacoemulsification and IOL implantation \\
\hline & & & $\begin{array}{l}\text { SEM and EDX analyses confirmed the presence of calcific deposits in the interior of the opacified hydrophilic IOLs, with a pattern showing the } \\
\text { formation of lumps on the surface }\end{array}$ \\
\hline \multirow[t]{5}{*}{ Werner Let al. (10) } & 3-piece PMM IOLs with snowflake degeneration $(n=5)$ & Gross and light microscopy & $\begin{array}{l}\text { Intraoptic changes, such as snowflake lesions in PMMA IOLs, calcification in hydrophilic acrylic IOLs, and glistenings in hydrophobic acrylic IOLs, } \\
\text { could be imaged by AS-OCT }\end{array}$ \\
\hline & Hydrophilic acrylic IOLs with calcification $(n=15)$ & AS - OCT & \multirow{4}{*}{$\begin{array}{l}\text { In cases of more superficial changes, unless the lesions/deposits were present on the optic surface with an extension to the optic substance of at } \\
\text { least } 0.1 \mathrm{~mm} \text {, they could not be clearly differentiated from the overall outline of the } 1 O L \text { surface }\end{array}$} \\
\hline & Silicone IOL with calcification in an eye with asteroid hyalosis $(n=1)$ & & \\
\hline & $\begin{array}{l}\text { Hydrophobic acrylic IOLs explanted because of decentration, } \\
\text { subluxation, or UGH syndrome with no observable optic } \\
\text { opacification }(n=5)\end{array}$ & & \\
\hline & 2 pseudophakic postmortem human eyes were assessed & & \\
\hline \multirow[t]{3}{*}{ Werner et al. (60) } & 7 hydrophilic acrylic IOLs explanted after DSEK or DSAEK & Gross and light microscopy & $\begin{array}{l}\text { Granular deposits were densely distributed in an overall round pattern within the margins of the capsulorhexis or the pupil on the anterior surface/ } \\
\text { subsurface of the IOLs }\end{array}$ \\
\hline & $\begin{array}{l}\text { The } 7 \text { explanted IOLs were represented by } 6 \text { hydrophilic acrylic } \\
\text { designs from } 5 \text { manufacturers }\end{array}$ & Scheimpflug photography was performed in 1 specimen & The granules stained positive for calcium \\
\hline & 1 noncalcified hydrophilic acrylic IOL used as a control & & Light scattering on the anterior optic surface of the explanted IOL was very high (228 vs. 13 CCT on a control IOL) \\
\hline \multirow[t]{2}{*}{ Espandar et al. (81) } & \multirow{2}{*}{$\begin{array}{l}3 \text { calcified silicone IOLs from } 2 \text { patients with a history of asteroid } \\
\text { hyalosis }\end{array}$} & Gross examination & \multirow{2}{*}{$\begin{array}{l}\text { The white deposits on the explanted IOLs formed an almost confluent crust in some areas, interspersed with clear areas on the posterior optic } \\
\text { surfaces }\end{array}$} \\
\hline & & Light microscopy & \\
\hline
\end{tabular}

Table 2 (Continued)

Light microscopy

Lithe white deposits on the explanted IOLs formed an almost confluent crust in some areas, interspersed with clear areas on the posterior optic 
Table 2 (Continued)

Authors

Stringham et al. (85) materias Gross examination

Light microscopy

were assessed for compariso Scanning electron microscopy

EDS

Giers et al. (71) 13 opacified hydrophilicloLs from 4 different manufacturers after posterior lamellar keratoplasty: 8 after DSAEK; 3 after DMEK; 2 after posterior lamellar keratop
both DSAEK and DMEK

Optical bench assessment for optical quality

Light microscopy Scanning electron microscopy

EDS

Schrittenlocher Retrospective review of charts and slit-lamp images of 564 consecutive patients from the prospective Cologne DMEK database who underwent DMEK in pseudophacic eyes or DMEK in combination with cataract surgery(triple-DMEK)

Patients with sufficient documentation during routine follow-up examinations with regard to calcifications analysis

Patients were grouped into affected group and unaffected group without calcifications of the $10 \mathrm{~L}$

Ahad et al. (76) A retrospective review of case notes from a single center of all patients undergoing DSAEK.

168 DSAEK were performed on 154 eyes of 137 patients.

54 cases had simultaneous cataract surgery with implantation of an IOL.

IOLs types included: Akreos Adapt, Rayner C or S flex, AcrySo Alcon MA50, Alcon SA60, and Rayner T Flex.

Marcovich et al. (61) 11 cases of hydrophilic IOLs hat opacified following PPV with intravitreal gas injection

OL types included: Hanita B lens, Xcellence Idea, Biotech vision care Eyecryl, Rayner Superflex Aspheric 920 hours, Rayner M-flex 630F , Zeiss CT Asphina 409M, U.S. optics SL- 902 , Rayner C-flex Aspheric 570C,

Ni Mhéalóid et al. (75) 4 cases of IOL anterior surface opacification are described in patients who required both cataract surgery and DSAEK.

IOL types: 1 hydrophilic acrylic lens with a hydrophobic surface Optics (AO)]; 1 hydrophilic acrylic IOL (Akreos Adapt AO); 1 unknow (hydrophilic)
Cases with IOL opacification were analyzed, and risk factors were identified

8 IOLs were explanted and analysed by light microscop and scanning electron microscopy, energy EDX (3 IOLs were not explanted)

Case reports analysis

The presence of asteroid hyalosis was confirmed in 13 cases (out of 10$)$

The deposits were only on the posterior optic surface of the silicone lenses and were composed of calcium and phosphate

An Nd:YAG laser posterior capsulotomy was performed in 12 cases a mean standard deviation of $7.57 \pm 4.21$ years after IOL implantation A history of asteroid hyalosis was not found in relation to any of the 111 cases of postoperative calcification of hydrophilic acrylic lenses

Macroscopically, all IOLs showed a more or less circular opacification of the central anterior optical surface, sparing the peripheral optical zone and the haptics

MTF measurements of 10 IOLs that were received with an intact optic showed a significant decrease in optical quality with MTF values deteriorate at all spatial frequencies

IOL calcifications after DMEK occurred in 14 patients (2.5\%)

Morphologically calcifications showed either diffuse clusters of small granular deposits or a denser configuration with sharp edges positioned in the pupillarycenter of the IOL

VA in affected and unaffected eyes were $0.33 \pm 0.24 \log$ MAR and $0.16 \pm 0.01 \log$ MAR after 3 months $(P<0.001)$ as well as $0.28 \pm 0.16 \log$ MAR an $0.13 \pm 0.08$ logMAR $(P<0.001)$ after 6 months, respectively

Affected eyes had an average of $1.14 \pm 0.77$ re-bubblings while in unaffected eyes $0.50 \pm 0.62$ rebubblings were performed $(\mathrm{P}=0.001)$

Patients with IOL calcifications had higher re-bubbling rates than patients without. Larger pupil diameters at the time of surgery showed a tendenoy to slightly larger areas of IOL calcifications

11 out of 14 (78.56 \%) affected eyes had hydrophilic acrylic IOLs, 2 affected eyes had hydrophobic acrylic IOL whereas one eye had a hydrophilic acrlic with hydrophobic surface

Fifteen (9.7\%) eyes developed IOL opacification

Calcification had a distinctive pattern, being limited to the anterior lens surface, in the pupillary zone

$53.3 \%(8 / 15)$ of the patients achieved VA of $6 / 12$ or better, and $33.3 \%(5 / 15)$ developed moderate visual loss due to the IOL opacification

The only statistically significant risk factor was rebubbling of detached endothelial grafts

Rebubbling was performed in $62.5 \%$ (10/15) of cases with IOL opacification, compared with 23\% (32/139) with no opacification (P=0.0009)

OL opacification was recorded 1 month to 6 years after PPV

OLs had opacified mainly anteriorly at the pupillary entrance or capsulorhexis opening

Light microscopy demonstrated granular surface deposits on the IOLs that stained positive for calcium by alizarin red and von Kossa stains

EDX analysis of the deposits detected calcium and phosphorus

Only one case had cataract surgery and DSAEK performed concurrently, with the remainder having DSAEK performed at variable timeframes after cataract surgery

All cases presented anterior surface IOL opacification after DSAEK

All cases had a complicated postoperative course

Two of the cases underwent lens explantation as a result of their distress

Table 2 (Continued) 
Table 2 (Continued)

Fung et al. (80) 7 hydrophilic actic
Superflex $620 \mathrm{H}$.

IOLs/Patien

Light microscopy Scanning electron microscopy

EDS

Gurabardhi et al. (11) 71 opacified 1-piece or 3-piece hydrophilic acrylic with a hydrophobic surface coating IOLs (Lentis) of different designs from $\mathrm{L}-312$

Light microscopy CDVA was assessed
Łabuz et al. (51)

4explanted hydrophilic acrylic IOLs (CT Asphina 409M/MP (Car Zeiss Meditec AG)

Control of CT Asphina 409MP IOL with a nominal power of $+21.0 D$ 8 explanted hydrophilic acrylic segmented refractive opacified IOL that was not explanted (in vivo)

Straylight

IOL models: LS-313 MF30 (5 cases), LS-312 MF30 (3 cases), and LS-313 MF15 (1 case)

Mean basic power 20.70 $\pm 2.30 \mathrm{D}$

Additional power of $+3.00 \mathrm{D}$ ( 8 cases) or $+1.50 \mathrm{D}(1$ case $)$

Control a clear MF30 lens

Yildirim et al. (62) 10 explanted IOLs: 5 CT Asphina 409M (Carl Zeiss Meditec AG, Germany); 3 Basis Z B1AW00 (1stQ, Germany); 1 C-flex Aspher

Control of clear hydrophilic $10 \mathrm{~L}$

CT Asphina 409M (+21.0 D), Basis Z B1AW00 (+18.5 D) C-flex Aspheric $970 \mathrm{C}(+26.0 \mathrm{D})$
3 patients had proliferative diabetic retinopathy, 1 had glaucoma

Anterior chamber inflammatory membranes developed between 1 and 4 weeks of surgery and were treated with intracameral rtPA

OL opacification was noted between 4 weeks and 6 years after rtPA treatment with reduced visual acuity, and IOL exchange was carried out in 3 patients

Diffuse fine granular deposits (confirmed as calcium and phosphate) on the anterior surface/subsurface of IOL optic

Morphological findings were surface, subsurface, or deep calcifications of the IOL material

The explanted IOLs exhibited a whitish discoloration within the opacified areas

Opacification was observed in the entire IOLs in some cases (optic and haptics), sometimes with clear localized areas, which were more pronounced in the optic-haptic junction areas in cases with 3-piece IOLs

Explantation was performed 4 years +1.2 after initial phacoemulsification

Ocular and systemic comorbidities were found without statistical correlation: the most frequent were diabetes, uveitis, and glaucoma The preoperative mean corrected distance visual acuity changed from $0.63 \pm 0.47$ logarithm of the minimum angle of resolution (logMAR) to $0.20 \pm 0.28$ logMAR postoperatively $(P<0.001)$

The loss of light in the calcified region was 0.27 in Case $1,0.64$ in Case 2, 0.50 in Case 3, and 0.45 in Case 4

The mean diameter of Ca granules $4.1 \mathrm{~mm} \pm 4.8,2.5 \pm 4.2 \mathrm{~mm}, 2.1 \pm 4.1 \mathrm{~mm}$, and $2.7 \pm 0.7 \mathrm{~mm}$ in Case 1, 2, 3, and 4, respectively 2 IOLs showed a significant drop in the MTF levels, with a lower Strehl ratio than that of the control IOL by $48 \%$ and $51 \%$ at $3 \mathrm{~mm}$ The straylight was extremely increased in 310 Ls up to (and above) a level of that of a cataractous lens

The average MTF (at $50 \mathrm{lp} / \mathrm{mm}$ ) value of the control and calcified IOLs was 0.36 and $0.34 \pm 0.03$ at far, and 0.30 and $0.29 \pm 0.01$ at near, respectively Straylight values significantly increased $\left(\mathrm{P}=0.01\right.$ ) in all of the opacified lenses, with a mean value of $170.1 \pm 71.5 \mathrm{deg}^{2} / \mathrm{sr}$ compared to the age-matched straylight level of the crystalline lens, which was $9.6 \pm 3.2 \mathrm{deg}^{2} / \mathrm{sr}$

In vivo optical performance of an eye with an opacified MF30 IOL: UDVA and UNVA of 20/20 and 20/25, an elevated straylight value of $199.5 \mathrm{deg}^{2} / \mathrm{s}$ $2.3 \log (\mathrm{s})]$

In all but one $10 \mathrm{~L}$ t two distinct foci could still be seen despite the opacification

8 cases showed opacification of the anterior surface of the IOL in and 2 cases showed opacification of the posterior surface

Crystalline deposits were found underneath the optical surface of the $\mathrm{IOL}$ with the diameter of 2-15 $\mu \mathrm{m}$

The MTF measurement could be performed in 9 out of 10 IOLs

At a 3-mm aperture, 6 of the 9 lenses showed a significantly lower optical quality at all special frequencies than that of a clear control IOL and a lower value $100 \mathrm{lp} / \mathrm{mm}$ than it is required by the ISO 11-979-2

At 4.5-mm, those IOLs also showed decreased MTF values as compared to their respective controls

Table 2 (Continued) 
Table 2 (Continued) Evaluated parameters/methodolog Results

$\begin{array}{lll}\text { Patel et al. (86) } & \begin{array}{l}12 \text { eyes that underwent retinal detachment repair after secondary } \\ \text { implantation of Akreos AO60 IOL with a subset experiencing the }\end{array} & \begin{array}{l}\text { Post-operative data included characteristics of IOL } \\ \text { opacification, length of follow-up and complications }\end{array}\end{array}$ complication of IOL opacification

Major predisposing risk factors for retinal detachment included trauma (42\%), prior vitrectomy (33\%), and ectopia lentils (17\%)

The procedure for surgical repair was vitrectomy without scleral buckle in 10 eyes $(83 \%)$ and combination vitrectomy and scleral buckle in two eyes

(42\%), 1000 centistoke silicone oil (25\%), C3F8 (25\%) and SF6 (8\%)

There were 5 cases $(42 \%)$ of permanent late IOL opacification

Opacification occurred in 2 of 4 eyes (50\%) with gas tamponade and 3 of 8 eyes (38\%) with oil tamponade

The average time to opacification was 46.2 days (range, 10-104 days)

Two eyes required explantation of the $\mathrm{OL}$

Photograph of an explanted IOL demonstrated diffuse tan, white calcium deposits on the lens optic and haptics

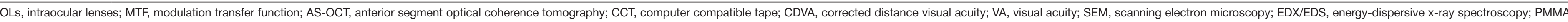

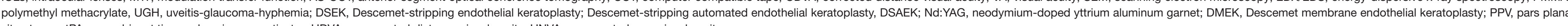

Table 3 The summary of risk factors for IOL glistenings and calcifications

\begin{tabular}{|c|c|c|c|}
\hline Type of IOL opacification & The material of IOLs & The breakdown of BAB & Ocular pathologies/surgeries \\
\hline Glistenings & Most often in hydrophobic lOLs & \multirow{2}{*}{$\begin{array}{l}\text { Diabetes; preservatives in glaucoma topical medications; postoperative } \\
\text { inflammation; complex or prolonged surgery }\end{array}$} & Glaucoma \\
\hline Calcifications & Most often in hydrophilic IOLs & & Intraocular injection of gas or air during DSEK, DSAEK, DMEK, PPV; Asteroid hyalosis (in silicone IOLs) \\
\hline
\end{tabular}

BAB, blood-aqueous barrier; DSEK, Descemet-stripping endothelial keratoplasty; DSAEK, Descemet-stripping automated endothelial keratoplasty; DMEK, Descemet membrane endothelial keratoplasty; PPV, pars plana vitrectomy. 
glistenings on visual function was focused on visual acuity. The majority of the reviewed studies that evaluated visual acuity did not find a significant glistening effect on visual acuity. However, one study, conducted by Matsushima et al. found that glistenings caused significantly decreased visual acuity in five patients, leading to IOL explantation (12). However, they did not perform statistical analysis to evaluate the changes in visual acuity (12). As well as all patients had ocular comorbidities: one had a history of uveitis, one had glaucoma, two had diabetic retinopathy, one macular hole, these last three cases had a history of PPV (12). It was reported that a 5 -fold increase in light scattering resulted only in a small decrease of $0.1 \mathrm{log}$ units in contrast sensitivity and had no effect on visual acuity $(38,56)$. This finding is similar to ours, as most of the studies did not find effect on visual acuity, some of the studies showed decreased contrast sensitivity $(16,39,44)$. The reduction of contrast sensitivity can be associated with the increase of straylight and disability glare. As more studies showed decreased contrast sensitivity than visual acuity, it could confirm that disability glare and straylight are more appropriate in evaluating IOLs opacification effect on visual quality.

That was seen in recent years studies that used the straylight measurement more commonly to evaluate the visual quality. All of the reviewed studies that measured straylight values showed a significant increase of straylight when opacification, including both glistenings and calcifications, were detected. The majority of the studies reported increased straylight values with a higher amount of glistenings $(20,38)$. However, few studies highlighted the importance of its size. Henriksen et al. performed an in vivo study with 79 patients and found the correlation between smaller size glistenings and increased light scattering (39). They also found that the age of the IOL had a negative correlation with the contrast visual acuity with glare and corrected distance visual acuity in patients group with smaller glistening size, suggesting that smaller glistenings had a more significant impact on visual function (39). However, they did not include and evaluate IOL opacification resulting in surface light scattering in their study, which could also have an impact on the reported results (39). It was reported by Philippaki and colleagues that the higher amount and smaller glistenings produced higher levels of straylight (13). The authors reported that the straylight of two out of five AcrySof IOLs exceeded that of the 70-year-old CIE standard glare observer, however, it was proposed that these high values could be caused by subsurface nanoglistenings which were not evaluated by the glistenings detection program (13). Although this study presented an important finding of glistenings size effect, the sample of the study is too small, also they did not report the threshold of glistening size and density which could have a significant impact on visual performance.

The majority of the studies did not present the exact levels of glistenings parameters or straylight values that would have a significant impact on certain visual performances. However, straylight values could be compared to the data found in the literature. The straylight level of a 20-year-old was reported to be $\mathrm{s}=2.5 \mathrm{deg}^{2} /$ steradian (sr), 70-year-old s $=11.2 \mathrm{deg}^{2} / \mathrm{sr}$, and cataractous $\mathrm{s}=33.1 \mathrm{deg}^{2} / \mathrm{sr}$ crystalline lens (51). It was reported that the hindrance of straylight could be $1.47 \log (\mathrm{s})$ (54). van der Mooren et al. defined that a lens with significant glistenings would be the lens that caused straylight levels above those of a healthy 20-year-old crystalline lens (85). Increased straylight by $19.0 \mathrm{deg}^{2} / \mathrm{sr}$ was reported to be associated with a $76 \%$ increase in halo size and a severe loss in luminance detection threshold (79).

Łabuz et al. found a proportional relationship between straylight, amount of glistenings, and the surface portion (38). They concluded that a large number of glistenings were needed to cause significant straylight increase (38). The same group of the authors conducted the other study and reported that $60 \%$ of thirty hydrophobic IOLs with in vitro induced glistenings had straylight values below that for the young lens (20). Only $20 \%$ reached light scattering levels with an average of $18.1 \mathrm{deg}^{2} / \mathrm{sr}$. that could have the potential to hinder visual performance (20). Łabuz et al. evaluated the light scattering in IOLs extracted from donors' eyes (21). They reported that the scattering intensity was higher than in the 70 -year-old lens in $14 \%$ of the IOLs, and none showed straylight values that could correspond to the cataractous lens (21). The median straylight values in donor IOLs were approximately 0.3 to $1.0 \log (\mathrm{s})\left(\mathrm{s}=2\right.$ to $\left.10 \mathrm{deg}^{2} / \mathrm{sr}\right)(21)$.

The majority of the studies were performed in vitro. Although studies used protocols for glistening induction by the thermal accelerated aging process with varying temperature and time setting, it was speculated that there is lack of evidence, if this method produces clinically relevant results. However, Łabuz et al. compared the highest straylight values of 3-piece IOLs from two studies: a study with glistenings induced in vitro and another study with IOLs extracted from donors' eyes. They also compared the glistening size, and the results were similar. Thus, 
the authors indicated that the scattering effect of in vitro induced glistenings can be compared to glistenings that form in vivo (20). The reviewed studies results showed that only a small part of IOLs with glistenings could have a significant effect on visual quality. Similar to that, subsurface nanoglistenings did not show a significant impact on visual performance as well. The two studies which evaluated subsurface nanoglistenings in vivo did not find a significant effect on visual acuity, although it increased light scattering $(43,57)$. However, Hiraoka et al. evaluated the backward light scattering, and it was reported that the relationship between forward scatter and backward scatter is weak $(43,87)$. Though, Werner et al. performed a study with seventeen IOLs with subsurface nanoglistenings which were removed from cadaver eyes and evaluated the forward light scattering (54). They found that straylight values in removed IOLs were higher than controls. However, none reached the value of $1.47 \log (\mathrm{s})$ as it was reported as a straylight hindrance level, which could have a severe impact on visual function (54).

Contrary to the straylight values of glistenings, calcified IOLs showed much higher straylight values, suggesting that it is a significant parameter to detect and evaluate opacification occurrence and its severity. The majority of the studies assessed backward scattering of calcified explanted IOLs, and only a few evaluated forward light scatterings. Łabuz et al. performed a study with four explanted calcified IOLs after intravitreal gas and air injection (51). They found the mean straylight parameter of $68.1 \mathrm{deg}^{2} / \mathrm{sr}$, however IOLs had a high variance of straylight values, which were associated with differences in opacification morphology (51). The similar straylight values with the mean straylight parameter of those IOLs at a 5 - to 10-degree angle was $47.9 \mathrm{deg}^{2} / \mathrm{sr}$ for the explanted hydrophilic IOLs were found in Werner et al. study $(51,88)$.

Yildirim et al. reported the mean straylight value of $170.1 \pm 71.5 \mathrm{deg}^{2} / \mathrm{sr}$ of eight explanted hydrophilic acrylic segmented refractive bifocal IOLs due to primary calcification (47). What is interesting that despite these high straylight values, most of the patients reported foggy and blurred vision, and the visual acuity was reported as good. However, that symptoms could be caused by bifocal IOLs, as they can induce these unwanted symptoms more often than monofocal IOLs. In a different study performed by the same researchers' group, two patients reported foggy vision, while half of them reported decreased vision before IOL explantation (62). Nevertheless, the majority of the reviewed studies reported a significant decrease in visual acuity that led to IOL explantation. Only one study and few single case reports did not show considerable calcification impact on visual acuity to that date of the study and the IOLs were not explanted $(61,68,75,76)$. In some of the cases, IOLs exchange were not performed due to the patients refusal or pore expectations of visual acuity improvement caused by concomitant ocular pathologies.

We believe that because it is clear from the past that calcification in hydrophilic materials affects visual function easily, it is not preferable to use hydrophilic materials for IOL until the mechanism of calcification and the preventive method are elucidated.

There is a strong association between light scattering, straylight and glare (89). The scattered light excites the photoreceptors in retina and degrade vision (89). The straylight is the visual effect seen as radiation around the point source of the light (89). It can cause disability glare which is associated with reduced retinal contrast leading to reduction of vision (90). Also, straylight effect can occur as hazy vision or decreased contrast sensitivity (91). Likewise, the straylight can decrease visual quality by inducing difficulties in face recognition, spatial orientation problems, contrast and color loss, however it hardly affects visual acuity (89). It was suggested that lenses opacities effect on vision should be evaluated by the assessment of disability glare rather than visual acuity (92). van den Berg et al. reported that glare have a limited impact only for the young eyes or low beams. For healthy older eyes, the problem was already significant with dimmed beams (90). This could suggest that glare could have a much higher impact on visual quality in eyes with ocular pathologies or abnormalities, as for example IOLs opacification, which induce straylight significantly. This could be confirmed by the fact that the majority of the calcified IOLs were explanted due to reduced visual performance. Although the majority of the reviewed studies showed high straylight values in explanted IOLs, however, patients reported not only decreased visual acuity, but also hazy, foggy vision. Glistenings effect on straylight was mostly evaluated during in vitro studies, the results and values of straylight were more likely considered to have a significant impact on visual quality at a certain level. However, most of the studies showed low percentage of affected IOLs by glistenings that could reduce visual performance.

The summary of studies results evaluating the impact of IOL glistenings and calcifications on visual quality is presented in Table 4.

Although many studies have focused on visual acuity 
Table 4 The summary of studies evaluating the impact of IOL glistenings and calcifications on visual quality

\begin{tabular}{|c|c|c|c|c|c|c|}
\hline \multirow{2}{*}{$\begin{array}{l}\text { Type of } 1 O L \\
\text { opacification }\end{array}$} & \multicolumn{2}{|c|}{ Visual acuity/contrast sensitivity } & \multicolumn{4}{|c|}{ Straylight } \\
\hline & Affected & Not affected & Affected & Not affected & Affected & Not affected \\
\hline \multirow[t]{8}{*}{ Glistening } & Reduced VA caused IOLs exchange (12) & $\begin{array}{l}\text { No significant differences in CDVA between the glistening severity } \\
\text { groups was found (33) }\end{array}$ & $\begin{array}{l}\text { Larger number of smaller glistenings produced more straylight than } \\
\text { the small number of larger glistenings (13) }\end{array}$ & \multirow[t]{8}{*}{ - } & \multirow{8}{*}{$\begin{array}{l}\text { Statistically significant } \\
\text { deterioration in the MTF was } \\
\text { reported in glistening grade } 4 \text { (52) }\end{array}$} & \multirow[t]{8}{*}{$\begin{array}{l}\text { MTF of IOLs with SSNGs were } \\
\text { similar to control values (54) }\end{array}$} \\
\hline & 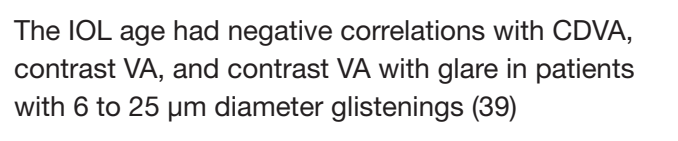 & $\begin{array}{l}\text { No correlation between the amount of glistenings and CS, CDVA, } \\
\text { or contrast sensitivity-CDVA was found (83) }\end{array}$ & $\begin{array}{l}\text { Straylight elevation demonstrated a proportional relationship with the } \\
\text { glistening number. Only in } 20 \% \text { the induced light scattering reached } \\
\text { levels that have the potential to hinder visual performance (20) }\end{array}$ & & & \\
\hline & $\begin{array}{l}\text { Higher glistening grade had significantly lower mean } \\
\text { CS values at high spatial frequencies }(41,44)\end{array}$ & $\begin{array}{l}\text { No difference was found in the CDVA and CS } 3 \text { years after } \\
\text { cataract surgery (35) }\end{array}$ & $\begin{array}{l}\text { A proportional relationship between the number of glistenings and } \\
\text { straylight was reported ( } 38 \text { ) }\end{array}$ & & & \\
\hline & & $\begin{array}{l}\text { Scattering light intensity of the surface and internal matrix did not } \\
\text { correlate with VA, contrast VA, or glare VA (16) }\end{array}$ & $\begin{array}{l}\text { Smaller glistening sizes, a similar \% area obscured by glistenings is } \\
\text { associated with increased light scatter ( } 39 \text { ) }\end{array}$ & & & \\
\hline & & $\begin{array}{l}\text { Increased surface light scattering had no significant impact on } \\
\text { CDVA (53) }\end{array}$ & \multirow{4}{*}{$\begin{array}{l}\text { The increased levels of straylight were not expected to be clinically } \\
\text { significant in terms of glare disability as they were below the } \\
\text { hindrance level (54) }\end{array}$} & & & \\
\hline & & Glistenings did not correlate with IOL power, CDVA, or CS (46) & & & & \\
\hline & & $\begin{array}{l}\text { No statistical correlation between glistening grades and IOLS } \\
\text { power, postoperative CDVA was reported }(44,46)\end{array}$ & & & & \\
\hline & & SSNGs did not induced any decline in standard VA $(43,55)$ & & & & \\
\hline \multirow[t]{3}{*}{ Calcification } & $\begin{array}{l}\text { All IOLs were explanted due to decreased VA } \\
(11,14,15,51,60,64,67,71)\end{array}$ & - & $\begin{array}{l}\text { Light scattering was extremely high and light transmittance was } \\
\text { significantly reduced in calcified IOLs (67) }\end{array}$ & - & $\begin{array}{l}\text { Significant reduction of MTF } \\
\text { values at all spatial frequencies } \\
\text { was reported. }(64,71)\end{array}$ & $\begin{array}{l}\text { Half of the explanted calcified } \\
\text { IOLs showed only minor MTF } \\
\text { changes (51) }\end{array}$ \\
\hline & \multirow{2}{*}{\multicolumn{2}{|c|}{$\begin{array}{l}33.3 \%(5 / 15) \text { of patients developed moderate visual } \\
\text { loss (less than } 6 / 12) \text {, they were not explanted }(76)\end{array}$}} & $\begin{array}{l}\text { Three of four explanted IOLs showed increased straylight up to (and } \\
\text { above) a level of that of a cataractous lens (51) }\end{array}$ & & & \multirow{2}{*}{$\begin{array}{l}\text { Despite calcification, } 7 \text { of } \\
8 \text { explanted IOLs showed } \\
\text { two distinct foci on the MTF } \\
\text { measurements (47) }\end{array}$} \\
\hline & & & Straylight values significantly increased in all of the opacified IOLs (47) & & & \\
\hline
\end{tabular}

VA, visual acuity: CS, contrast sensitivity; MTF, modulation transfer function: IOLs, intraccular lenses; CDVA, corrected distance visual acuity; BCWA, be 
and contrast sensitivity, relatively little effects were found. van den Berg et al. reported that visual acuity and straylight are independent factors with their impact on visual quality with no significant correlation between them (93). They also concluded that aberrations and micro-aberrations are responsible for the loss of visual acuity due to cataract or other opacities, but not straylight (93). However, straylight induces other problems, which we discussed previously while making it an important part of the quality of vision. It is insufficiently realized that visual acuity or contrast sensitivity are measured using highly artificial tests, so the proper way to assess the visual function effects could be through straylight or light scattering.

The limitation of the majority of reviewed studies based on calcification is the low number of cases and the lack of prospective studies. Contrary to that researches based on glistenings included a higher number of cases in retrospective studies, however a significant part of the studies was performed in vitro, which are considered to produce low reliable evidence.

\section{Conclusions}

Glistening occur more often than calcification, but usually, it does not cause a significant decrease in visual acuity that would lead to IOL exchange. The incidence of IOLs calcification is low, however, it significantly reduces vision quality, leading to IOLs explantation. Results of recently reported studies show that particular surgeries, such as DSEK, DSAEK, DMEK and PPV with intraocular gas or air injection, might predispose the calcification process. The authors suggest surgeons being aware of the fact that calcification is more common in hydrophilic acrylic IOLs. However, it was reported that both types of opacification significantly increase straylight, which might result in hazy, foggy vision, or difficulties in dynamic light conditions, leading to persistent visual complaints. Straylight levels depend on opacification size and density, which might be determined by different factors, including IOLs material, manufacturing and packaging processes, concomitant ocular pathologies, inflammatory factors.

The identification and better understanding of possible risk factors and how does opacifications affect visual quality could be useful for future investigations as well as for clinical practice. This could lead to the solutions of avoidance or elimination of opacifications formation while evaluating the most significant and specific factors of visual quality.

\section{Acknowledgments}

Funding: None.

\section{Footnote}

Provenance and Peer Review: This article was commissioned by the Guest Editor (Dr. Andrzej Grzybowski) for the series "Recent developments in cataract surgery" published in Annals of Translational Medicine. The article was sent for external peer review organized by the editorial office.

Reporting Checklist: The authors have completed the Narrative Review Reporting Checklist. Available at http:// dx.doi.org/10.21037/atm-20-4207

Conflicts of Interest: All authors have completed the ICMJE uniform disclosure form (available at http:// dx.doi.org/10.21037/atm-20-4207). The series "Recent developments in cataract surgery" was commissioned by the editorial office without any funding or sponsorship. AG served as the unpaid Guest Editor of the series. The authors have no other conflicts of interest to declare.

Ethical Statement: The authors are accountable for all aspects of the work in ensuring that questions related to the accuracy or integrity of any part of the work are appropriately investigated and resolved.

Open Access Statement: This is an Open Access article distributed in accordance with the Creative Commons Attribution-NonCommercial-NoDerivs 4.0 International License (CC BY-NC-ND 4.0), which permits the noncommercial replication and distribution of the article with the strict proviso that no changes or edits are made and the original work is properly cited (including links to both the formal publication through the relevant DOI and the license). See: https://creativecommons.org/licenses/by-nc-nd/4.0/.

\section{References}

1. Stanojcic N, Hull C, O'Brart DP. Clinical and material degradations of intraocular lenses: A review. Eur J Ophthalmol 2020;30:823-39.

2. Almost 5 million cataract surgeries in the EU in 2017 2019. Available online: https://ec.europa.eu/eurostat/web/ products-eurostat-news/-/DDN-20191204-1

3. Cari Pérez-Vives. Biomaterial Influence on Intraocular 
Lens Performance: An Overview. J Ophthalmol 2018;2018:2687385.

4. Özyol P, Özyol E, Karel F. Biocompatibility of Intraocular Lenses. Turk J Ophthalmol 2017;47:221-5.

5. Astbury N, Nyamai LA. Detecting and managing complications in cataract patients. Community Eye Health 2016;29:27-9.

6. Apple DJ, Escobar-Gomez M, Zaugg B, et al. Modern Cataract Surgery: Unfinished Business and Unanswered Questions. Surv Ophthalmol 2011;56:S3-S53.

7. Vock L, Menapace R, Stifter E, et al. Posterior capsule opacification and neodymium:YAG laser capsulotomy rates with a round-edged silicone and a sharp-edged hydrophobic acrylic intraocular lens 10 years after surgery. J Cataract Refract Surg 2009;35:459-65.

8. Johansson B. Glistenings, anterior/posterior capsular opacification and incidence of Nd:YAG laser treatments with two aspheric hydrophobic acrylic intraocular lenses - a long-term intra-individual study. Acta Ophthalmol 2017;95:671-7.

9. Bellucci R. An Introduction to Intraocular Lenses: Material, Optics, Haptics, Design and Aberration. ESASO Course Series. Basel, Karger: Cataract 2013;3:38-55.

10. Werner L, Michelson J, Ollerton A, et al. Anterior segment optical coherence tomography in the assessment of postoperative intraocular lens optic changes. J Cataract Refract Surg 2012;38:1077-85.

11. Gurabardhi M, Häberle H, Aurich H, et al. Serial intraocular lens opacifications of different designs from the same manufacturer: clinical and light microscopic results of 71 explant cases. J Cataract Refract Surg 2018;44:1326-32.

12. Matsushima H, Nagata M, Katsuki Y, et al. Decreased visual acuity resulting from glistening and sub-surface nano-glistening formation in intraocular lenses: A retrospective analysis of 5 cases. Saudi J Ophthalmol 2015;29:259-63.

13. Philippaki E, O'Brart DP, Hull CC. Comparison of glistenings formation and their effect on forward light scatter between the AcrySof SN60WF and Eternity Natural Uni NW-60 intraocular lenses. BMJ Open Ophthalmol 2020;5:e000399.

14. Gartaganis SP, Prahs P, Lazari ED, et al. Calcification of Hydrophilic Acrylic Intraocular Lenses With a Hydrophobic Surface: Laboratory Analysis of 6 Cases. Am J Ophthalmol 2016;168:68-77.

15. Bompastor-Ramos P, Póvoa J, Lobo C, et al. Late postoperative opacification of a hydrophilic-hydrophobic acrylic intraocular lens. J Cataract Refract Surg 2016;42:1324-31.

16. Hayashi K, Hirata A, Yoshida M, et al. Long-term effect of surface light scattering and glistenings of intraocular lenses on visual function. Am J Ophthalmol 2012;154:240-51.e2.

17. Khurana AK, Raj A, Bahadur H. Comparison of Posterior Capsular Opacification with Hydrophilic and Hydrophobic Acrylic Posterior Chamber Intraocular Lens after Cataract Surgery. J Clin Diagn Res 2017;11:13-6.

18. Leydolt C, Schartmueller D, Schwarzenbacher L, et al. Posterior capsule opacification with two hydrophobic acrylic intraocular lenses: 3-year results of a randomized trial. Am J Ophthalmol 2020. doi:10.1016/ j.ajo.2020.04.011.

19. Kahraman G, Ferdinaro C, Wetzel B, et al. Intraindividual comparison of capsule behavior of 2 hydrophobic acrylic intraocular lenses during a 5-year follow-up. J Cataract Refract Surg 2017;43:228-33.

20. Łabuz G, Knebel D, Auffarth GU et al. Glistening Formation and Light Scattering in Six HydrophobicAcrylic Intraocular Lenses. Am J Ophthalmol 2018;196:112-20.

21. Łabuz G, Reus NJ, van den Berg TJ. Light scattering levels from intraocular lenses extracted from donor eyes. J Cataract Refract Surg 2017;43:1207-12.

22. Van Den Berg TJ, Van Rijn LJ, Michael R, et al. Straylight effects with aging and lens extraction. Am J Ophthalmol 2007;144:358-63.

23. Werner L, Thatthamla I, Ong M, et al. Evaluation of clarity characteristics in a new hydrophobic acrylic IOL in comparison to commercially available IOLs. J Cataract Refract Surg 2019;45:1490-7.

24. Grzybowski A, Kanclerz P, Beiko GHH. IOLs glistenings and quality of vision. Graefes Arch Clin Exp Ophthalmol 2019;257:2795-6.

25. Kato K, Nishida M, Yamane H, et al. Glistening formation in an AcrySof lens initiated by spinodal decomposition of the polymer network by temperature change. J Cataract Refract Surg 2001;27:1493-8.

26. Saylor DM, Coleman RD, Dair BJ, et al. Osmotic cavitation of elastomeric intraocular lenses. Acta Biomater 2010;6:1090-8.

27. Rønbeck M, Behndig A, Taube M, et al. Comparison of glistenings in intraocular lenses with three different materials: 12-year follow-up. Acta Ophthalmol 2013;91:66-70.

28. Werner L. Glistenings and surface light scattering in intraocular lenses. J Cataract Refract Surg 
2010;36:1398-420.

29. Manuchehri K, Mohamed S, Cheung D et al. Brown deposits in the optic of foldable intraocular lenses in patients with uveitis. Eye 2004;18:54-8.

30. Nishihara H, Yaguchi S, Onishi T, et al. Surface scattering in implanted hydrophobic intraocular lenses. J Cataract Refract Surg 2003;29:1385-8.

31. Matsushima H, Mukai K, Nagata M, et al. Analysis of surface whitening of extracted hydrophobic acrylic intraocular lenses. J Cataract Refract Surg 2009;35:1927-34.

32. Ong MD, Callaghan TA, Pei R, et al. Etiology of surface light scattering on hydrophobic acrylic intraocular lenses. J Cataract Refract Surg 2012;38:1833-44.

33. Tognetto D, Toto L, Sanguinetti G, et al. Glistenings in foldable intraocular lenses. J Cataract Refract Surg 2002;28:1211-6.

34. Colin J, Praud D, Touboul D, et al. Incidence of glistenings with the latest generation of yellow-tinted hydrophobic acrylic intraocular lenses. J Cataract Refract Surg 2012;38:1140-6.

35. Miyata K, Ogata M, Honbo M, et al. Suppression of surface light scattering in intraocular lenses manufactured using an improved production process. J Cataract Refract Surg 2016;42:1716-20.

36. Packer M, Rajan M, Ligabue E, et al. Clinical properties of a novel, glistening-free,single-piece, hydrophobic acrylic IOL. Clin Ophthalmol 2014;8:421-7.

37. Leydolt C, Schriefl S, Stifter E, et al. Posterior capsule opacification with the imics1 ny-60 and ACRYSOF sn60wf 1-piece hydrophobic acrylic intraocular lenses: 3 -year results of a randomized trial. Am J Ophthalmol 2013;156:375-81.e2.

38. Łabuz G, Reus NJ, van den Berg TJ. Straylight from glistenings in intraocular lenses: In vitro study. J Cataract Refract Surg 2017;43:102-8.

39. Henriksen BS, Kinard K, Olson RJ. Effect of intraocular lens glistening size on visual quality. J Cataract Refract Surg 2015;41:1190-8.

40. DeHoog E, Doraiswamy A. Evaluation of the impact of light scatter from glistenings in pseudophakic eyes. J Cataract Refract Surg 2014;40:95-103.

41. Schweitzer C, Orignac I, Praud D, et al. Glistening in glaucomatous eyes: visual performances and risk factors. Acta Ophthalmol 2014;92:529-34.

42. Mönestam E, Behndig A. Impact on visual function from light scattering and glistenings in intraocular lenses, a long-term study. Acta Ophthalmol 2011;89:724-8.
43. Hiraoka T, Miyata K, Hayashidera T, et al. Influence of intraocular lens subsurface nanoglistenings on functional visual acuity. PLoS One 2017;12:e0173574.

44. Xi L, Liu Y, Zhao F, et al. Analysis of glistenings in hydrophobic acrylic intraocular lenses on visual performance. Int J Ophthalmol 2014;7:446-51.

45. Godlewska A, Owczarek G, Jurowski P. Glistening phenomenon in acrylic hydrophobic intraocular lenses - how do perioperative factors and concomitant diseases effect it's incidence and severity. Klin Oczna 2016;118:191-6.

46. Chang A, Kugelberg M. Glistenings 9 years after phacoemulsification in hydrophobic and hydrophilic acrylic intraocular lenses. J Cataract Refract Surg 2015;41:1199-204.

47. Yildirim TM, Labuz G, Khoramnia R, et al. Impact of Primary Calcification in Segmented Refractive Bifocal Intraocular Lenses on Optical Performance Including Straylight. J Refract Surg 2020;36:20-7.

48. Łabuz G, Vargas-Martín F, van den Berg TJ, et al. Method for in vitro assessment of straylight from intraocular lenses. Biomed Opt Express 2015;6:4457-64.

49. van den Berg TJ, Franssen L, Kruijt B, et al. History of ocular straylight measurement: A review. Z Med Phys 2013;23:6-20.

50. van den Berg TJ. Intraocular light scatter, reflections, fluorescence and 365 absorption: what we see in the slit lamp. Ophthalmic Physiol Opt 2018;38:6-25.

51. Łabuz G, Yildirim TM, van den Berg TJTP, et al. Assessment of straylight and the modulation transfer function of intraocular lenses with centrally localized opacification associated with the intraocular injection of gas. J Cataract Refract Surg 2018;44:615-22.

52. Weindler JN, Łabuz G, Yildirim TM, et al. The impact of glistenings on the optical quality of a hydrophobic acrylic intraocular lens. J Cataract Refract Surg 2019;45:1020-5.

53. Miyata K, Honbo M, Otani S, et al. Effect on visual acuity of increased surface light scattering in intraocular lenses. J Cataract Refract Surg 2012;38:221-6.

54. Werner L, Stover JC, Schwiegerling J, et al. Light scattering, straylight, and optical quality in hydrophobic acrylic intraocular lenses with subsurface nanoglistenings. J Cataract Refract Surg 2016;42:148-56.

55. Beheregaray S, Yamamoto T, Hiraoka T, et al. Influence on visual function of forward light scattering associated with subsurface nanoglistenings in intraocular lenses. J Cataract Refract Surg 2014;40:1147-54.

56. van den Berg T, Franssen L, Coppens J. Ocular 
media clarity and straylight. Oxford, Academic Press: Encyclopedia of the Eye 2010:173-83.

57. Alarcon A, Canovas C, Rosen R, et al. Preclinical metrics to predict through-focus visual acuity for pseudophakic patients. Biomed Opt Express 2016;7:1877-88.

58. Son HS, Labuz G, Khoramnia R, et al. Ray propagation imaging and optical quality evaluation of different intraocular lens models. PLoS One 2020;15:e0228342.

59. Neuhann IM, Kleinmann G, Apple DJ. A new classification of calcification of intraocular lenses. Ophthalmology 2008;115:73-9.

60. Werner L, Wilbanks G, Nieuwendaal CP, et al. Localized opacification of hydrophilic acrylic intraocular lenses after procedures using intracameral injection of air or gas. $\mathrm{J}$ Cataract Refract Surg 2015;41:199-207.

61. Marcovich AL, Tandogan T, Bareket M, et al. Opacification of hydrophilic intraocular lenses associated with vitrectomy and injection of intraocular gas. BMJ Open Ophthalmol 2018;3:e000157.

62. Yildirim TM, Auffarth GU, Łabuz G, et al. Material Analysis and Optical Quality Assessment of Opacified Hydrophilic Acrylic Intraocular Lenses After Pars Plana Vitrectomy. Am J Ophthalmol 2018;193:10-9.

63. Dagres E, Khan MA, Kyle GM, et al. Perioperative complications of intraocular lens exchange in patients with opacified Aqua-Sense lenses. J Cataract Refract Surg 2004;30:2569-73.

64. Tandogan T, Khoramnia R, Choi CY, et al. Optical and material analysis of opacified hydrophilic intraocular lenses after explantation: a laboratory study. BMC Ophthalmol 2015;15:170.

65. Platt SM, Iezzi R, Mahr MA, et al. Surgical removal of dystrophic calcification on a silicone intraocular lens in association with asteroid hyalosis. J Cataract Refract Surg 2017;43:1608-10.

66. Choudhry S, Goel N, Mehta A, et al. Anterior segment optical coherence tomography of intraocular lens opacification. Indian J Ophthalmol 2018;66:858-60.

67. Barra D, Werner L, Costa JL, et al. Light scattering and light transmittance in a series of calcified single-piece hydrophilic acrylic intraocular lenses of the same design. J Cataract Refract Surg 2014;40:121-8.

68. Ma ST, Yang CM, Hou YC. Postoperative intraocular lens opacification. Taiwan J Ophthalmol 2018;8:49-51.

69. Schrittenlocher S, Penier M, Schaub F, et al. Intraocular lens calcifications after (triple-) Descemet membrane endothelial keratoplasty. Am J Ophthalmol 2017;179:129-36.
70. Nieuwendaal CP, van der Meulen IJE, Patryn EK, et al. Opacification of the intraocular lens after Descemet stripping endothelial keratoplasty. Cornea 2015;34:1375-7.

71. Giers BC, Tandogan T, Auffarth GU, et al. Hydrophilic intraocular lens opacification after posterior lamellar keratoplasty - a material analysis with special reference to optical quality assessment. BMC Ophthalmol 2017;17:150.

72. Milojcic C, Latz C, Tandogan T, et al. Opacification of a hydrophilic acrylic intraocular lens after DMEK: A material analysis. Ophthalmologe 2017;114:832-7.

73. Fellman MA, Werner L, Liu ET, et al. Calcification of a hydrophilic acrylic intraocular lens after Descemetstripping endothelial keratoplasty: case report and laboratory analyses. J Cataract Refract Surg 2013;39:799-803.

74. Lee MS, Tsai IL, Tsai CY, et al. Intraocular lens opacification after Descemet's stripping automated endothelial keratoplasty. Taiwan J Ophthalmol 2017;7:160-3.

75. Ní Mhéalóid Á, Fulcher T, O’Keefe M. Anterior surface opacification of intraocular lenses after Descemet's stripping automated endothelial keratoplasty. BMJ Case Rep 2015;2015:bcr2015213216.

76. Ahad MA, Darcy K, Cook SD, et al. Intraocular lens opacification after descemet stripping automated endothelial keratoplasty. Cornea 2014;33:1307-11.

77. Morgan-Warren PJ, Andreatta W, Patel AK. Opacification of hydrophilic intraocular lenses after descemet stripping automated endothelial keratoplasty. Clin Ophthalmol 2015;9:277-83.

78. Khurana RN, Werner L. Calcification of a Hydrophilic Acrylic Intraocular Lens after Pars Plana Vitrectomy. Retin Cases Brief Rep 2018;12:204-6.

79. van der Mooren M, Rosen R, Franssen L, et al. Degradation of Visual Performance With Increasing Levels of Retinal Stray Light. Invest Ophthalmol Vis Sci 2016;57:5443-8.

80. Fung SS, Sykakis E, Islam NM, et al. Intraocular Lens Opacification following Intracameral Injection of Recombinant Tissue Plasminogen Activator to Treat Inflammatory Membranes after Cataract Surgery. J Ophthalmol 2015;2015:975075.

81. Espandar L, Mukherjee N, Werner L, et al. Diagnosis and management of opacified silicone intraocular lenses in patients with asteroid hyalosis. J Cataract Refract Surg 2015;41:222-5.

82. Thomes BE, Callaghan TA. Evaluation of in vitro glistening formation in hydrophobic acrylic intraocular 
lenses. Clin Ophthalmol 2013;7:1529-34.

83. Chang A, Behndig A, Rønbeck M, et al. Comparison of posterior capsule opacification and glistenings with 2 hydrophobic acrylic intraocular lenses: 5- to 7-year followup. J Cataract Refract Surg 2013;39:694-8.

84. van der Mooren M, Franssen L, Piers P. Effects of glistenings in intraocular lenses. Biomed Opt Express 2013;4:1294-304.

85. Stringham J, Werner L, Monson B, et al. Calcification of different designs of silicone intraocular lenses in eyes with asteroid hyalosis. Ophthalmology 2010;117:1486-92.

86. Patel NA, Fan KC, Yannuzzi NA, et al. Akreos AO60 Intraocular Lens Opacification Following Retinal Detachment Repair. Ophthalmology Retina 2020. Available online: https://doi.org/10.1016/ j.oret.2020.03.030

87. Łabuz G, Reus NJ, van den Berg TJ. Ocular straylight in the normal pseudophakic eye. J Cataract Refract Surg 2015;41:1406-15.

Cite this article as: Grzybowski A, Markeviciute A, Zemaitiene R. A narrative review of intraocular lens opacifications: update 2020. Ann Transl Med 2020;8(22):1547. doi: $10.21037 /$ atm-20-4207
88. Werner L, Stover JC, Schwiegerling J, et al. Effects of Intraocular Lens Opacification on Light Scatter, Stray Light, and Overall Optical Quality/Performance. Invest Ophthalmol Vis Sci 2016;57:3239-47.

89. Artal P. Handbook of Visual Optics, Two-Volume Set. Boca Raton: CRC Press, 2017.

90. van den Berg TJ, René van Rijn LJ, Kaper-Bongers R, et al. Disability Glare in the Aging Eye. Assessment and Impact on Driving. J Optom 2009;2:112-8.

91. Mueller-Schotte S, van der Schouw YT, Schuurmans MJ. Ocular Straylight: A Determinant of Quality of Life in the Elderly? Gerontol Geriatr Med 2015. DOI: 10.1177/2333721415610193.

92. Bailey IL, Bullimore MA. A new test for the evaluation of disability glare. Optom Vis Sci 1991;68:911-7.

93. van den Berg TJ. The (lack of) relation between straylight and visual acuity. Two domains of the point-spreadfunction. Ophthalmic Physiol Opt 2017;37:333-41. 